\title{
ALGUNAS NOTAS SOBRE EL CONSUMO Y COMERCIALIZACIÓN DE TEJIDOS EN CASTILLA A COMIENZOS DEL SIGLO XVII: LA ENCUESTA DE 1618*
}

\author{
JOSÉ IGNACIO ANDRÉS UCENDO \\ Universidad del País Vasco ${ }^{a}$
}

\begin{abstract}
RESUMEN
El presente artículo ofrece algunas notas sobre el consumo y la comercialización de textiles en varias áreas de Castilla en las primeras décadas del siglo XVII a partir de una nueva fuente documental: la encuesta de 1618. La primera parte expone las características de la fuente documental. En la segunda se analizan las transacciones de tejidos atendiendo a la fibra empleada en su elaboración. La tercera parte presenta algunas notas sobre la tipología de los tejidos vendidos en Castilla en 1614-16. Esto nos permite analizar las áreas de comercialización de dos géneros representativos de la pañería castellana: los paños segovianos y los de Córdoba, Úbeda y Baeza. Por último, a partir del estudio del consumo de tejidos por vecino en varios partidos y distritos y del análisis de las relaciones de intercambio entre los precios del trigo y los de varios tejidos en 1614-16 se detectan
\end{abstract}

\footnotetext{
* Este trabajo se ha realizado gracias al proyecto de investigación de la Universidad del País Vasco 1/UPV 00012.130-HA, «Consumo y niveles de vida en el País Vasco, 1500-1860». Deseo expresar mi agradecimiento a Isabel Aguirre Landa por haberme advertido de la importancia del legajo 2.145 de la Cámara de Castilla. Igualmente, también quisiera hacer constar mi agradecimiento a Santiago Piquero y Ramón Lanza, así como a los evaluadores anónimos por sus observaciones, que me han ayudado a mejorar la calidad de este artículo. Por supuesto, cualquier defecto de las presentes líneas es de mi única responsabilidad.

a Departamento de Historia e Instituciones Económicas. Facultad de Filología, Geografía e Historia. Paseo de la Universidad 5. E-01006Vitoria. JUCENDO@terra.es
} 
varios indicios que apuntan a unos niveles de consumo de tejidos más elevados en Andalucía que en Castilla la Vieja.

Palabras clave: Castilla, consumo, comercialización, tejidos, manufactura

\begin{abstract}
This article deals with the consumption and marketing of textiles in some Castilian areas during the first decades of the $17^{\text {th }}$ century. The study uses a new documentary source: the 1618 inquiry. Part one describes the main characteristics of this documentary source. The second part analyzes textiles sales according to the fibre the different fabrics were made of. The third part presents some notes on the typology of the textiles sold in the country. This allows us to describe the marketing areas of two highly representative products of the Castilian woollen industry: the Segovian and Andalusian cloth. Finally, in the fourth and last part we have estimated the consumption of textile fabrics by household. This analysis has also been completed with a study of the terms of trade between grain and some textile fabrics between 1614 and 1616. The results support the hypothesis of a higher consumption of textile products in Andalusia than in Old Castile at the beginning of the $17^{\text {th }}$ century.
\end{abstract}

Keywords: Castile, consumption levels, marketing, textiles, manufacture JEL Classification: N01, N33, N63, N73, N93

\title{
1. INTRODUCCIÓN
}

La decadencia de la manufactura textil a lo largo del Seiscientos constituye uno de los temas más destacados de la historia económica y social de Castilla en la Edad Moderna, como atestiguan las obras, ya clásicas, de Carande (1990), Iradiel (1974) y Ruiz Martín (1965 y 1966), junto con las más recientes de García Sanz (1977 y 1990) y Casado (1990), que han reconstruido los principales rasgos del sector en los siglos XV y XVI. A éstas deben añadirse las aportaciones del ya citado García Sanz (1977), así como las de Bilbao y Fernández de Pinedo (1993) acerca de las causas de las dificultades del textil en la crisis del XVII, sin olvidar los capítulos dedicados a esta manufactura en los trabajos de historia regional de autores como Weiser (1971 y 1973), Fortea (1981) y Montemayor (1996), y el reciente libro de Miralles (2002) sobre la sedería murciana. Gracias a estos trabajos se ha trazado una convincente imagen global sobre la trayectoria del sector que 
ha sido el punto de partida de investigaciones posteriores, en la que destacan dos fases: a la expansión del textil -tanto lanero como sedero- del siglo XVI sucedió una decadencia, consolidada en la primera mitad del siglo XVII, sin que los cambios y reconversiones operados pudieran devolver a esta actividad su antiguo esplendor.

En las últimas décadas los análisis sobre el textil han ampliado su tradicional objeto de estudio. La preocupación por la decadencia del sector en el Seisicientos sigue viva, pero en el contexto del marcado interés exhibido por la historiografía internacional en las últimas décadas por el estudio de los salarios reales y los niveles de vida en el período preindustrial también han proliferado las investigaciones sobre la comercialización y el consumo de tejidos en nuestro país en la Edad Moderna. Estas investigaciones se han centrado en los siglos XVI, como atestiguan los artículos de H. Casado sobre las redes de venta de textiles en Castilla en el Quinientos, y XVIII, período para el que hay varios trabajos sobre el consumo y distribución de tejidos en Castilla y Cataluña, siendo digna de mención la escasez de investigaciones sobre estos aspectos en la Castilla del Seiscientos ${ }^{1}$.

El objeto de las líneas que siguen es contribuir a paliar esta carencia a través de la presentación y análisis de una fuente inédita: el legajo 2.145 de la Cámara de Castilla, conservado en el Archivo General de Simancas. Este documento conserva las respuestas de quince de las dieciocho ciudades con voto en Cortes a una encuesta encargada por el Arzobispo de Burgos, Presidente del Consejo de Castilla, en la cual se les preguntaba, entre otras cosas, por el valor monetario, el precio y el volumen de los tejidos de lino, lana y seda vendidos en sus distritos a lo largo del trienio 1614-1616. El segundo apartado expone las características de la fuente. A continuación, la tercera parte estudia el valor y el volumen de las ventas de tejidos según la fibra empleada en su elaboración, perspectiva completada en el cuarto apartado con una aproximación a la tipología de los textiles que figuraban en las ventas. Esto permite obtener, desde un punto de vista descriptivo, una imagen que refleja algunas pautas en la comercialización y ventas de tejidos en varias áreas castellanas en 1614-16.

Las investigaciones sobre el consumo y la riqueza material en la Europa preindustrial a partir de fuentes como los inventarios post mortem han mostrado una tendencia al aumento en la posesión de bienes de consumo que podría interpretarse como prueba de una mejora en los niveles de vida. Sin embargo, los estudios sobre los salarios indican que a lo largo de la Edad Moderna éstos tendieron a caer en términos reales, lo que contradice la imagen anterior. Para explicar esta paradoja se han invocado algunos elementos que no son excluyentes entre

${ }^{1}$ Vid . Casado Alonso (1990) y (2001), Durán Pujol (2003), Hoyo Aparicio y Maruri Villanueva (2003), Ramos Palencia (2003), Torra Fernández (1997), (2002) y (2003), así como los trabajos en el volumen editado por Yun y Torras (1999). 
sí, como el desarrollo de la llamada industrious revolution y el diverso comportamiento de los precios relativos de los productos agrícolas y manufactureros ${ }^{2}$. En lo que al caso español se refiere, F. Ramos ha comprobado que entre 1750 y 1840 hubo un alza moderada pero significativa en el consumo de textiles por parte de las clases medias urbanas y rurales palentinas, algo que explica por el avance de la economía de mercado y el paralelo retroceso de la agricultura de subsistencia -en consonancia con lo indicado por los defensores de la industrious revolution- y por el descenso de la relación de intercambio entre los precios de los textiles y los productos agrícolas ${ }^{3}$.

Centrada en el trienio 1614-16, nuestra fuente no permite estudiar cómo evolucionó el consumo de tejidos a lo largo del XVII. En contrapartida, a partir del análisis de las relaciones de intercambio entre los precios de la fanega de trigo y de varios tejidos en localidades de las provincias de Jaén, Ávila, algunos partidos sorianos y en la ciudad de Valladolid en 1614-16, realizado en la quinta y última parte, se obtienen indicios que sugieren reseñables contrastes regionales en el consumo de textiles. Esto permite apuntar a modo de hipótesis algunos elementos que pueden ayudar a mejorar nuestra comprensión de las dificultades del textil castellano atendiendo a factores del lado de la demanda.

\section{CARACTERÍSTICAS DE LA FUENTE}

En el tránsito del siglo XVI al XVII la manufactura textil castellana comenzó a manifestar síntomas de dificultades, lo que despertó el interés de arbitristas como Sancho de Moncada y Damián de Olivares, en cuyas obras se defendía una política proteccionista que protegiera a las ciudades manufactureras del interior de la competencia de los tejidos foráneos ${ }^{4}$. La preocupación por este problema también se extendió a las instituciones de gobierno de la Monarquía y a las Cortes de Castilla, como atestigua la discusión a lo largo de 1617 de un ambicioso proyecto de reforma fiscal consistente en rebajar las sisas y cargas monetarias recaudadas desde 1601 para la cobranza del servicio de millones, introduciendo nuevos gravámenes sobre los tejidos, cera, azúcares y papel que «entrasen o saliesen por los puertos» ${ }^{5}$.

${ }^{2}$ Van Zanden (1999, pp. 190 y 191). En cuanto al concepto de industrious revolution, vid. De Vries (1994).

${ }^{3}$ Ramos Palencia (2003, pp. 173-175).

${ }^{4}$ Sobre las dificultades del textil castellano en este período vid., entre otros, Bilbao y Fernández de Pinedo (1993, pp. 137 ss.).

${ }^{5}$ Actas de las Cortes de Castilla (A.C.C.), vol. XXX, p. 442 y vol. XXXI, pp. 430-431. 
A fin de disponer de una estimación del valor de un recargo sobre las transacciones de los productos arriba citados, el Presidente del Consejo de Castilla envió el 28 de noviembre de 1617 una carta a los corregidores de las ciudades con voto en Cortes en la cual les ordenaba averiguar las cantidades de azúcar, papel, cera y tejidos vendidas en sus distritos a lo largo del trienio 1614-16. En lo que a los tejidos se refiere, deberían indicar el precio de venta de cada uno, el volumen y el monto de las transacciones. Las respuestas a la carta comenzaron a llegar a lo largo de diciembre de 1617, y se puede afirmar que la operación estaba acabada en los primeros meses de 1618. Los corregidores de las capitales de provincia se encargaron de recopilar las informaciones relativas a sus corregimientos y enviaron traslados de la carta del Presidente del Consejo de Castilla a los demás corregimientos de las provincias para que sus colegas reuniesen la información requerida.

Pronto se vio que esta labor era más difícil de lo que pudiera pensarse a simple vista. La administración de los Austrias siempre mantuvo, incluso en los momentos más graves de la crisis del siglo XVII, un elevado nivel de eficiencia, del que son buena muestra fuentes tan famosas para la historia económica y social de Castilla como los vecindarios de 1591 y 1631 . No obstante, las condiciones y los medios técnicos de la época imponían algunos límites a los que ni siquiera esta eficiente burocracia podía escapar. La extensión de algunos distritos en los que se enclavaba un gran número de ciudades, villas y pueblos constituía uno de los más destacados y, no por casualidad, los corregidores de Burgos, Zamora y León, tres provincias que en conjunto tenían cerca de 10.000 núcleos de población, advirtieron de la tardanza en recibir las respuestas de sus provincias.

Por otra parte, aunque la carta del Presidente de Castilla no lo indicara explícitamente, parecía claro que el propósito de los promotores del plan era imponer un recargo sobre la alcabala devengada por los paños, cera, papel y azúcar. Quizá por este motivo la primera reacción de muchos corregidores fue revisar los documentos relativos a la cobranza de este tributo. Sin embargo, pronto se detectaron los defectos de este tipo de fuentes. Debido a la extensión del sistema de encabezamientos, con frecuencia no había una relación directa entre el monto de la alcabala y los tejidos vendidos, algo que se pudo comprobar en las ciudades de Madrid, Guadalajara, León, Burgos, Valladolid y en las villas de Medina de Rioseco y Arévalo y la mayor parte de la provincia de Zamora.

La tradicional resistencia de comerciantes y hombres de negocios a revelar cualquier tipo de información sobre sus actividades fue otro de los obstáculos a los que se enfrentaron los delegados regios. Ante los problemas de los libros de encabezamientos, los corregidores de Zamora, León, Toro, Jaén, Ávila y Valladolid optaron por consultar los libros de cuentas de los mercaderes. Sin embargo, en núcleos como la ciudad de León o en Arévalo, así como en las villas feriales de Medina del Campo y Medina de Rioseco, los comerciantes no llevaban libros de caja, mientras que en Valladolid y Zamora sólo se registraban las ventas al fiado, 
pero no las efectuadas al contado, lo que podía causar una notable infravaloración del volumen de ventas

Ante los problemas que acabamos de señalar, la solución más común fue completar la información de los libros de alcabalas con el recurso en cada localidad al testimonio de testigos, entre los cuales con frecuencia estuvieron los propios comerciantes, salvo excepciones como la de la ciudad de Granada, cuyo corregidor empleó los aforos de los paños comercializados en la capital andaluza en 161416, así como los datos de los diezmos de la seda.

Teniendo en cuenta lo anterior, es fácil comprender que la calidad de las respuestas fue variable. No han llegado hasta nosotros, por razones que desconocemos, los informes de las provincias de Toledo, Cuenca y Murcia, mientras que la respuesta de Salamanca apenas posee interés. A su vez, los corregidores de Madrid y Burgos se limitaron a copiar el valor de los miembros de la alcabala recaudada en ambas ciudades. Conocemos los valores globales de las ventas de tejidos, cera, azúcar y papel de las provincias de Córdoba y Segovia -a excepción, en este último caso, de la capital-, aunque el documento no indica de forma separada las sumas correspondientes a cada producto. Por lo que se refiere a las respuestas de las demás provincias, en la mayoría de los casos poseen un carácter impresionista, aportando datos de innegable interés acerca de diversas facetas del textil castellano, pero sin permitir un tratamiento cuantitativo. Sin embargo, las respuestas de varias localidades de las provincias de Sevilla, Jaén, Granada, Zamora, Ávila, León y Valladolid, junto con las de algunos partidos de Soria y Toro y la provincia de Guadalajara, con las cuales se ha elaborado el Apéndice 1, ayudan a resolver este inconveniente. Estas respuestas se formularon a partir de las informaciones de los libros de alcabalas y recogen el valor monetario de las ventas trienales de paños, lienzos y tejidos de seda. A esto se debe sumar que en algunas villas y lugares de las provincias de Jaén y Ávila, así como en varios partidos sorianos y en la villa segoviana de Sepúlveda, se ofrecen datos pormenorizados acerca del volumen, el tipo y el precio de los tejidos vendidos (Apéndice 2).

Antes de proseguir conviene recordar que la fuente no está exenta de carencias. Aparte de las ya citadas, nos gustaría destacar dos. En primer lugar, es sabido que la competencia ejercida por la entrada de productos extranjeros fue un factor esencial en los problemas de la pañería no sólo castellana, sino también de otras regiones como Cataluña ${ }^{6}$. Aunque no falten algunas menciones a la presencia de paños foráneos, la fuente no indica el origen de los paños vendidos, lo que impide medir su peso, algo que no sucede en el caso de los lienzos, cuyo nombre nos permite establecer su origen con razonable seguridad ${ }^{7}$.

\footnotetext{
${ }^{6}$ Para el caso catalán, vid. Durán Pujol (2003, p. 65).

${ }^{7}$ Por poner un ejemplo, el documento cita la presencia de courtrais entre los paños vendidos en el partido de Soria, y la de paños de Londres en el aforo de la ciudad de Granada.
} 
En segundo lugar, la falta de información sobre las grandes ciudades del Reino como Madrid y Sevilla constituye la carencia de mayor relieve del legajo 2.145, por lo que resultaría aventurado afirmar que la fuente permite un análisis general sobre la comercialización y el consumo de textiles en Castilla. Sin embargo, hechas estas salvedades, pensamos que a partir del análisis de los datos contenidos en los apéndices 1 y 2 se pueden presentar algunas notas que permiten acercarnos a un mejor conocimiento de varias pautas en la comercialización y consumo de tejidos en una muestra de localidades y partidos de varias provincias de Castilla la Vieja y Andalucía.

\section{EL VALOR Y EL VOLUMEN DE TEJIDOS VENDIDOS SEGÚN LA FIBRA}

Es bien sabido que, en una época desconocedora de las fibras artificiales como era el Antiguo Régimen, los tejidos se elaboraban mediante fibras como el lino, la seda y la lana. La información almacenada en la fuente nos ha permitido construir el Cuadro 1, en el que se han agrupado los tejidos comercializados a lo largo del trienio objeto de estudio según su valor monetario y la fibra, estableciendo el peso de los géneros de lino, lana y seda, tanto en términos absolutos como porcentuales. Los datos de Sevilla, Granada, Jaén, Zamora y León corresponden a varias localidades de estas provincias. El cuadro también muestra los valores de la provincia de Guadalajara y los de algunos partidos de las provincias de Soria y Toro, junto con los de un pequeño grupo de núcleos de Ávila y las villas de Sepúlveda y Peñafiel.

Para clasificar los tejidos se ha recurrido a las definiciones del Diccionario de Autoridades, así como al reciente libro de Carmen Bernis (2001) acerca de los trajes y los tipos sociales en tiempos del Quijote, y, sobre todo, a una minuciosa relación del corregidor de Valladolid con el nombre y el precio de los tejidos vendidos en su ciudad en el trienio 1614-16, contenida en el legajo.

Gracias al empleo de las fuentes que acabamos de citar, esta labor no ha planteado excesivas dificultades, aunque debemos reseñar dos aspectos. Siguiendo el criterio del Corregidor de Valladolid, en primer lugar, hemos optado por incluir dentro de la lencería algunos géneros como los caniquíes, los bofetanes, las cotonías, bombasis, fustanes y bocacíes, en muchos casos elaborados total o parcialmente con algodón. Tanto en términos de valor como de volumen, el peso de estos textiles no era muy elevado, lo cual ha constituido otra razón que nos ha animado a respetar la conducta del Corregidor de Valladolid. En segundo lugar, hemos excluido de las ventas de los tejidos de seda las transacciones de seda en bruto o torcida, lo que hace que en el Cuadro 1 no se hayan usado las respuestas de las ciudades de Jaén y Baeza, ya que en las mismas las ventas de estos dos tipos de productos estaban mezcladas. 


\section{CUADRO 1}

VALOR TRIENAL DE LAS VENTAS DE TEJIDOS EN CASTILLA, 1614-1616 (maravedís)

\begin{tabular}{|c|c|c|c|c|}
\hline PROVINCIA & Lana & Seda & Lino & TOTAL \\
\hline Sevilla & 34.856 .064 (34) & $21.105 .510(20,7)$ & 45.921 .702 (45) & $101.883 .276(100)$ \\
\hline Jaén & $22.004 .055(70)$ & $3.897 .340(12,4)$ & $5.421 .900(17,3)$ & 31.323 .295 (100) \\
\hline Granada & $11.582 .289(51)$ & $2.888 .646(12,6)$ & $8.222 .251(36,2)$ & $22.693 .186(100)$ \\
\hline ANDALUCÍA & $68.442 .408(44)$ & 27.891.496 (17,8) & $59.565 .853(38)$ & 155.899.757 (100) \\
\hline Zamora & $31.292 .013(72)$ & $5.315 .076(12,2)$ & $6.732 .260(15,5)$ & 43.339.349 (100) \\
\hline Toro & 5.189 .352 (69) & $708.288(9,4)$ & $1.611 .600(21,4)$ & $7.509 .240(100)$ \\
\hline Soria & $9.026 .984(70,7)$ & $1.618 .912(12,6)$ & $2.103 .734(16,4)$ & $12.749 .630(100)$ \\
\hline León & $14.053 .089(77,4)$ & $2.124 .997(11,7)$ & $1.955 .386(10,7)$ & $18.133 .472(100)$ \\
\hline Ávila & $5.182 .596(82)$ & $284.376(4,4)$ & $859.945(13,5)$ & $6.326 .917(100)$ \\
\hline Segovia & $1.346 .400(85,8)$ & 43.350 (3) & $178.500(11,3)$ & $1.568 .250(100)$ \\
\hline Valladolid & $307.020(68,3)$ & 116.859 (26) & $25.368(5,6)$ & $449.247(100)$ \\
\hline C. LA VIEJA & $66.397 .454(73,6)$ & $10.211 .858(11,3)$ & 13.466 .793 (15) & $90.076 .105(100)$ \\
\hline Guadalajara & 27.982 .884 (77) & 4.780 .842 (13) & $3.774 .476(10,3)$ & $36.538 .202(100)$ \\
\hline TOTAL & $162.822 .746(57,6)$ & 42.884.196 (15) & 76.807.122 (27) & $282.514 .064(100)$ \\
\hline
\end{tabular}

Fuente: Apéndice 1

SEDA: tejidos de seda (seda en hilo, pasamanos, pasamanos de oro y plata, tafetanes, oro y plata hilados, telas de oro y plata, terciopelo, rasos, mantos de seda, cintas y puntas). LANA: tejidos de lana (paños finos de Segovia, paños veintidosenos de Segovia, paños veinticuatrenos de Córdoba y Baeza, paños de Jaén, dieciochenos, catorcenos, secenos, bayetas, bayetas de Flandes y de Sevilla, paños pardos y de la tierra, paños burieles, paños de Londres, cariseas, cilicios, anascotes, estameñas, cordellates, frisas, rajas, rajuelas, picotes, courtrais, perpetuanes, sayas, mezclas, jergas y jerguillas). LINO: lienzos (lienzos, angeos, holandas, ruanes, ruanetes, bocacis, bofetanes, bombasis, tocas, lienzos navales, cambrais, caniquíes, manteles, fustanes, telillas, lienzos de cáñamo y estopa).

El Cuadro 1 indica que las ventas de paños ocupaban el lugar mayoritario, seguidas de los lienzos y tejidos de seda. Esta distribución es muy similar a la registrada en otros momentos y regiones. Así, a partir del estudio de los textiles que figuraban en los inventarios post mortem en la provincia de Palencia a la altura de 1750, F. Ramos indica que la lana representaba el 55 por cien de los tejidos empleados en la confección de prendas, el lino el 35 por cien, y la seda el 9 por cien ${ }^{8}$. En otras regiones como Cataluña la situación era similar: según el análisis de L.Torra de los inventarios de 45 botiguers de Barcelona, en 1650 la fibra más utilizada en los tejidos vendidos fue la lana, seguida del lienzo y, en tercer lugar, de la seda ${ }^{9}$.

${ }^{8}$ Ramos Palencia, (2003, p. 158, cuadro 8).

${ }^{9}$ Torra, (2002, p. 17, cuadro 2). 
El escaso valor de las ventas de tejidos de seda, que puede resultar sorprendente cuando se recuerda la importancia de la que gozaba la industria y el comercio de este género en la Castilla de la época ${ }^{10}$, se explica por la falta de datos acerca de los grandes centros de consumo y producción, como las ciudades de Sevilla, Córdoba, Jaén, Toledo y Granada. En cuanto a los paños, bajo su superioridad, normal en las economías del Antiguo Régimen, se encubren algunos contrastes de interés. En las villas y partidos de Castilla la Vieja eran el tejido predominante -73,6 por cien-, pero su peso se reducía al 44 por cien en las localidades andaluzas. Por lo que se refiere a Castilla la Nueva, sin duda la región peor cubierta por la fuente, los datos de Guadalajara son análogos a los de Castilla la Vieja. Sin embargo, sería aventurado pretender que la estructura de las ventas de las demás provincias de la región fuera similar a la del distrito alcarreño. La fuente no da informaciones acerca de Madrid y guarda silencio sobre Toledo. Cuando se recuerda que la capital era, junto con la ciudad de Sevilla, el mayor centro de consumo del Reino, por un lado, y que Toledo todavía albergaba una destacada industria sedera, por el otro, resulta fácil concluir que el peso de los tejidos de seda marcaría con su huella la estructura de las ventas en estas provincias, mientras que la de Cuenca estaría más cerca de la de Castilla la Vieja.

Esta precisión no empaña el contraste entre Castilla la Vieja y Andalucía, donde la importancia de los lienzos constituye el hecho de mayor relieve, aunque es preciso resaltar que esto se debe, sobre todo, al peso de este tejido en los lugares sevillanos, en comparación con lo sucedido en Jaén, cuyas transacciones poseían una estructura parecida a la de Castilla la Vieja y Guadalajara. La presencia en el Cuadro 1 de varias localidades de la tierra de Baeza, uno de los principales centros de la pañería meridional, como Bejíjar, Jabalquinto, Torres, Garcés, Albanches y Bedmar, donde estaba muy difundida la labranza de paños bastos para el autoconsumo campesino, y de villas como Linares, Bailén, Huelma y Alcalá la Real, en donde se tejían paños de mejor calidad y al mismo tiempo se vendían los géneros de Baeza y Córdoba, explica la preponderancia de los paños en las ventas de la provincia andaluza. Por su parte, la importancia de los lienzos en los lugares sevillanos no se debe a que sus ventas se concentraran en uno o dos lugares. Más bien sucede lo contrario, puesto que en nueve de las trece localidades sevillanas analizadas, las transacciones de este tejido representaban el 40 por cien o más del total, destacando el caso de Écija, donde ascendían al 63 por cien. Estos porcentajes sugieren que el consumo de lienzos debía estar muy difundido en los demás lugares de la provincia, comenzando por la capital, Sevilla, en donde no en vano el gremio de comerciantes de lienzos había sido una de las corporaciones más destacadas de la ciudad a lo largo del siglo XVI ${ }^{11}$.

\footnotetext{
${ }^{10}$ Para la industria y el comercio de la seda a lo largo de este período, vid. Carande (1990) y Garzón Pareja (1972).

${ }^{11}$ Véanse Bernal, Collantes de Terán y García Baquero (1978, pág. 234 y cuadro 34).
} 
Atendiendo al peso de los lienzos, la provincia de Granada estaba más cerca de Sevilla que de Jaén a causa de la importancia de este producto en varias localidades del sur y del litoral. Las transacciones de lienzos representaban el 42 por cien del total en Ronda, el 51 por cien en Vera y el 52 y el 55 por cien en Motril y Marbella, respectivamente (Apéndice 1), lo cual parece indicar que, en el vestuario de los habitantes de las zonas meridionales de la Corona de Castilla, las prendas de lino, bien adaptadas a las condiciones climáticas de la región, tenían un lugar de relieve.

Lo anterior certifica el relevante papel de los lienzos en las ventas y el consumo de textiles en la Corona de Castilla en las primeras décadas del siglo XVII, sobre todo en las áreas meridionales del país. Debe recordarse que el Cuadro 1 analiza las transacciones de textiles atendiendo a su precio y que, por lo general, el de los lienzos era muy inferior al de los paños. Si además atendemos al volumen de textiles comercializados -en número de varas-, el peso de los géneros de lino adquiere más realce. Esto nos ha animado a elaborar el Cuadro 2, en donde se muestra la distribución porcentual de las transacciones de textiles según el valor monetario y el volumen en un conjunto de localidades de las provincias de Ávila y Jaén, así como en varios partidos de Soria y en la villa de Sepúlveda. La ligera diferencia en los valores monetarios de las ventas de la provincia de Soria en los cuadros 1 y 2 se explica porque, en general, las respuestas indicaban el valor de las transacciones, siendo mucho menos frecuente que los pueblos mencionaran el número de varas vendidas. Esto hace que en el Cuadro 2 no se hayan recogido los datos de algunos partidos sorianos -Calahorra, Nalda y Atienza- que sí aparecen en el 1. Además, debe aclararse que el reducido peso de los tejidos de seda, medido en términos de volumen, se explica porque algunos productos de esta fibra, como los pasamanos, la seda hilada, los mantos de seda y, en ocasiones, los tafetanes se vendían por libras y onzas. Estos géneros representaban el 35 por cien del valor de las ventas de textiles de seda de los lugares del Apéndice 2, por lo que el volumen de esta clase de tejidos está infravalorado. Por el contrario, el volumen de los paños y lienzos se expresaba en varas, aunque hubiera algunas excepciones, como los anascotes, perpetuanes y calzas -paños- y los caniquíes, bombasis y telillas -lienzos-, que se medían por piezas. Como la importancia de estos tejidos era pequeña, los datos del Cuadro 2 relativos a paños y lienzos pueden considerarse muy fiables: los anascotes, perpetuanes y calzas representaban el 1 por cien del valor de las ventas de paños de los lugares del Apéndice 2, y los caniquíes, bombasis y telillas apenas llegaban al 0,5 por cien del valor de las transacciones de lienzos.

Los resultados obtenidos del Cuadro 2 confirman que, en todos los distritos, la importancia de los lienzos, medida según el volumen, era muy superior a lo que se pudiera pensar si sólo se atendiera al valor monetario, acortándose la diferencia que les superaba de los paños. Esto avala el peso de este producto en la 


\section{CUADRO 2 \\ ESTRUCTURA EN TÉRMINOS ABSOLUTOS Y PORCENTUALES DE LAS VENTAS DE TEJIDOS SEGÚN VALOR Y VOLUMEN. CASTILLA, 1614-1616 (maravedís y varas)}

\begin{tabular}{|l|c|c|c|c|c|c|}
\hline \multirow{4}{*}{ Jaén } & \multicolumn{2}{|c|}{ Paños } & \multicolumn{2}{c|}{ Sedas } & \multicolumn{2}{c|}{ Lienzos } \\
\cline { 2 - 7 } & $\begin{array}{c}\text { Valor } \\
\text { (maravedís) }\end{array}$ & $\begin{array}{c}\text { Volumen } \\
\text { (varas) }\end{array}$ & $\begin{array}{c}\text { Valor } \\
\text { (maravedís) }\end{array}$ & $\begin{array}{c}\text { Volumen } \\
\text { (varas) }\end{array}$ & $\begin{array}{c}\text { Valor } \\
\text { (maravedís) }\end{array}$ & $\begin{array}{c}\text { Volumen } \\
\text { (varas) }\end{array}$ \\
\cline { 2 - 7 } & $18.052 .555\left(70^{*}\right)$ & $49.215\left(50^{*}\right)$ & $3.552 .154\left(13,7^{*}\right)$ & $6.875\left(7^{*}\right)$ & $4.137 .800\left(16^{*}\right)$ & $42.230\left(43^{*}\right)$ \\
Ávila & $5.182 .596\left(82^{*}\right)$ & $20.655\left(60^{*}\right)$ & $284.376\left(4,4^{*}\right)$ & $2.140\left(6,2^{*}\right)$ & $859.945\left(13,5^{*}\right)$ & $11.555\left(34^{*}\right)$ \\
Soria & $7.093 .176\left(76^{*}\right)$ & $17.756\left(59^{*}\right)$ & $1.000 .426\left(10,7^{*}\right)$ & $1.247\left(4^{*}\right)$ & $1.207 .972\left(13^{*}\right)$ & $10.991\left(36,6^{*}\right)$ \\
Sepúlveda & $1.346 .400\left(86^{*}\right)$ & $3.600\left(61,5^{*}\right)$ & $43.350\left(3^{*}\right)$ & $150\left(2,5^{*}\right)$ & $178.500\left(11^{*}\right)$ & $2.100\left(36^{*}\right)$ \\
\hline
\end{tabular}

Fuente: Apéndice 2.

Nota: * Los números entre paréntesis indican porcentajes sobre los totales de cada provincia.

comercialización y el consumo de los habitantes del Reino a inicios del XVII, no sólo en las provincias más meridionales del país, sino también en los distritos y localidades de Castilla la Vieja, y ayuda a entender la preocupación manifestada por las instituciones de gobierno de la Monarquía y por los tratadistas a lo largo del período por la entrada de lienzos foráneos.

\section{UNA APROXIMACIÓN A LA TIPOLOGÍA DE LOS TEJIDOS VENDIDOS}

El Apéndice 2 recoge las clases de tejidos vendidos en varias localidades de las provincias de Jaén y Ávila, así como en seis partidos de la provincia de Soria y en la villa segoviana de Sepúlveda, lo que nos permite averiguar cuáles eran los productos textiles más comunes en las transacciones de un conjunto de localidades sobre las que disponemos buena información, y presentar algunas notas sobre la tipología de los tejidos que formaban parte de las ventas.

Es sabido que el comercio de los tejidos de seda había conocido un gran desarrollo en Castilla en el siglo XVI, por lo que existía una gran variedad de productos de esta fibra. Por citar un ejemplo, según el informe del Corregidor de Valladolid, a lo largo del trienio 1614-1616 se habían vendido treinta y cinco clases de tejidos de seda en su ciudad. En contraste con esta variedad, el Apéndice 2 sólo registra las ventas de un reducido número de productos, sobre todo telas de oro y plata, listones, terciopelos, pasamanos y tafetanes, cuyo precio no era demasiado elevado -si exceptuamos los terciopelos, vendidos a 30-40 reales la vara-. Sin duda, los más comunes eran los pasamanos y los tafetanes. Los primeros representaban el 18 por cien del valor de las ventas de los tejidos de seda en los lugares del Apéndice 2, mientras que los tafetanes, destinados, según las respues- 
tas de varios pueblos de Jaén, a la confección de adornos en los vestidos de los campesinos, alcanzaban el 40 por cien, siendo el tejido de seda más vendido ${ }^{12}$. No es aventurado afirmar que esta escasa variedad constituye un buen reflejo de una demanda campesina con escaso poder de compra, algo indicado en las respuestas de varias localidades jienenses -como Albanches, Bedmar, Garcés, Torrequebradilla y Cambil- donde se aludía explícitamente a la pobreza de sus moradores «respeto de la gran necesidad que a abido los años pasados y este presente».

En cuanto a los paños, del Apéndice 2 y los cuadros 3 y 4 se extraen algunos elementos de interés. El Cuadro 3 indica los paños vendidos en las ciudades de Jaén y Ronda en 1614-1616, mientras que el 4 es una copia del aforo de los vendidos en la ciudad de Granada en las mismas fechas. Siendo el aforo una operación en la que se verificaba la cantidad y el valor de los tejidos entrados en la ciudad antes de someterlos al pago de los impuestos reales y municipales, pensamos que aporta una imagen fiel de las transacciones de paños en la capital andaluza.

La presencia de los paños segovianos en los distritos de Castilla la Vieja del Apéndice 2 constituye uno de los hechos de más relieve. Sus ventas se mencionan en Oropesa, Soria, El Burgo de Osma, Alfaro y, posiblemente, en Talavera la Vieja, y, además, el legajo 2.145 también cita ventas de este producto en Ávila, Carrión de los Condes, Toro, Valladolid, Calahorra, Galicia, León, Asturias y en algunas ciudades andaluzas como Jaén, Ronda, Málaga y Cádiz.

Los paños segovianos, buenos representantes de la pañería urbana castellana, eran géneros de calidad media-alta, como los paños veintidosenos y limiste, con los que se abastecían las necesidades de las clases medias y acomodadas de las ciudades y villas del interior peninsular ${ }^{13}$. Según acabamos de citar, se vendían en Oropesa y en partidos como Soria y El Burgo de Osma, que albergaban ciudades y villas de cierta entidad. En el partido de Soria se enclavaba la capital provincial, la cual, aunque no pudiera compararse con las grandes ciudades del Reino, gozaba del privilegio de voto en Cortes, mientras que El Burgo de Osma era una sede episcopal. Estos hechos se reflejan en la estructura de las transacciones de paños de los dos partidos, caracterizada por el peso -en términos de valor- de los géneros de la ciudad del Eresma. En los dos casos, el paño más vendido era el veintidoseno segoviano, cuyas ventas representaban el 32,4 por cien del valor del total de las transacciones de paños en Soria y el 34 por cien en El Burgo.

Ya hemos señalado la ubicuidad de los paños segovianos. Sin embargo, debe resaltarse que, en los distritos de los que tenemos datos, las ventas de este pro-

${ }^{12}$ La importancia de los tafetanes dentro de las ventas de los tejidos de seda ha sido constatada en otras regiones como Cataluña. Torra (1997, pp. 188-89) y Durán Pujol (2003, pp. 76-77).

${ }^{13}$ Véanse García Sanz (1977, p. 214) y (1990, p. 165). 
ducto se concentraban en los partidos de Soria y El Burgo de Osma -más la villa de Oropesa- y que, de hecho, en el conjunto de los partidos de Castilla la Vieja del Apéndice 2, el paño segoviano apenas representaba el 3 por cien de los paños vendidos y el 10,4 por cien del valor de las ventas. A esto se debe añadir que su peso en los distritos andaluces era todavía menor, lo que sugiere que los paños más consumidos en Castilla a inicios del XVII no eran los segovianos, sino la amplia variedad de paños bastos y baratos empleados por la mayoría de la población del país para satisfacer sus necesidades.

El veintidoseno segoviano poseía un carácter tradicional, siendo la dura competencia ejercida por los productos foráneos de la nueva pañería, de menor calidad pero también más baratos, una de las causas de los problemas de este tipo de producción. En un esfuerzo por adaptarse al nuevo contexto, los fabricantes segovianos y otros como los palentinos adoptaron medidas para incentivar la fabricación de paños más baratos, como las bayetas, de modo que en 1625 los productores segovianos y palentinos firmaron un acuerdo con la Corona para impulsar la labranza de este producto, y la fuente aporta algunos datos para calcular la importancia de este tipo de paño en las primeras décadas del siglo XVII ${ }^{14}$. A la altura del trienio 1614-16 se habían vendido en Soria y El Burgo 941 varas de bayetas segovianas, lo que significaba el 15 por cien del valor de las transacciones de paños y el 16 por cien del volumen en ambos distritos. Se trataba de porcentajes importantes, aunque debe resaltarse que en los partidos y localidades de Castilla la Vieja del apéndice el peso de las bayetas segovianas era reducido -apenas representaban el 2,4 por cien del volumen de los paños vendidos y el 4,5 por cien del valor-, lo que indica la modestia de este cambio a inicios del siglo XVII.

El Apéndice 2 muestra que los textiles segovianos no figuran en las transacciones de los núcleos más ruralizados, como los lugares de la tierra de Oropesa, Navalmorquende, La Puebla de Naciados, Sepúlveda y los partidos de Ágreda y Medinaceli, donde, como era de suponer, el peso de los paños más baratos en las ventas resultaba aplastante. Los géneros más difundidos en estos centros eran la amplia gama de paños pardos, bastos, burieles, secenos, catorcenos, frisas y cordellates. En buena parte de los casos estos tejidos eran producidos por los propios campesinos para atender las necesidades de su autoconsumo, lo que sucedía en Ágreda, Alfaro, Navalmorquende y su tierra, La Puebla de Naciados y los lugares de Oropesa ${ }^{15}$.

El contraste entre el tipo de paños vendidos en los distritos en que se enclavaban las villas y núcleos de mayor tamaño y las zonas más ruralizadas de Castilla

${ }^{14}$ García Sanz (1977, p. 220).

${ }^{15}$ Los lugares de Oropesa pueden ser considerados como parte del área pañera del sur de Ávila, donde se enclavaban otros centros como Piedrahita y El Barco de Ávila. Véase Casado (1990, pp. 535-536). 
la Vieja también es perceptible en las localidades jienenses del Apéndice 2, aunque esto no debe ocultar la presencia de diferencias de relieve entre las dos zonas.

En los lugares y villas más pequeñas como Baños, Jabalquinto, Torres, Albanches, Bedmar, Garcés y Cotillas, las transacciones se limitaban a paños y bayetas, a menudo tejidos por los campesinos, cuyo precio era por lo general 11 rs/vara. Más variedad había en las villas de mayor tamaño, como Villafranca, Bailén y Alcalá la Real, donde destacaban los paños veinticuatrenos, dieciochenos y catorcenos, seguidos por las bayetas, perpetuanes, frisas, rajas, picotes, anascotes y estameñas. A su vez, en las ciudades de Jaén y Ronda se vendían sobre todo paños de Baeza y Córdoba -veinticuatrenos y dieciochenos- y, en menor medida, bayetas, estameñas y frisas. Siendo el veinticuatreno el producto más destacado de la pañería meridional, resulta desafortunado que en las respuestas de ambas ciudades se mezclen las ventas de veinticuatrenos y dieciochenos, aunque, gracias a los datos de Granada, sabemos que los primeros representaron, en términos de valor, el 36 por cien del aforo de los paños vendidos en la ciudad andaluza en 1614-1616, lo que hacía de este género el paño más destacado.

El escaso relieve de los paños segovianos en Jaén, Granada y Ronda constituye uno de los hechos más destacados de los cuadros 3 y 4 . Al reducido peso de los géneros segovianos en estas ciudades corresponde la importancia de las ventas de veinticuatrenos, el producto estrella de una pujante industria pañera desarrollada a lo largo del Quinientos en un área que abarcaba varias localidades de la provincia de Córdoba y Jaén, llegando por el norte a los medios rurales de La Mancha y Toledo. Entre los núcleos más destacados del ditrito hay que citar Córdoba, Úbeda y Baeza, cuyos géneros gozaron de gran difusión en las ciudades andaluzas ${ }^{16}$. Según la fuente, los veinticuatrenos vendidos en Jaén, Alcalá la Real y Villafranca procedían de Córdoba y Baeza, y el legajo también cita la venta de paños de Baeza -posiblemente veinticuatrenos- en otras ciudades y villas andaluzas, como Cádiz y Moguer. Pero la fabricación de este producto no se concentraba en las ciudades, dado que su obraje también estaba difundido en los medios rurales de Toledo, La Mancha y Córdoba, áreas a las que cabría añadir la provincia de Jaén, en donde localidades como Huelma, Linares, Cambil, Villanueva de Andújar y Jimena albergaban su propia producción de veinticuatrenos.

Por otro lado, es interesante recordar que la actividad pañera de las localidades jienenses citadas en la fuente mostraba rasgos similares a los de la pañería cordobesa en su fase de de expansión. Al lado de una producción de baja calidad -dieciochenos y catorcenos- se desarrollaba otra de mayor calidad -veinticuatrenos $^{17}$. Villas como Bailén, Huelma, Alcalá la Real y Villafranca labraban

\footnotetext{
${ }^{16}$ Sobre la pañería cordobesa, vid. Fortea Pérez (1981, pp. 278 ss).

17 Ibidem (pp. 309 ss.).
} 
CUADRO 3

PAÑOS VENDIDOS EN JAÉN Y RONDA, 1614-1616

(maravedís y varas)

\begin{tabular}{|l|c|c|c|c|}
\hline \multirow{2}{*}{ Tipo de paño } & \multicolumn{2}{|c|}{ Jaén } & \multicolumn{2}{c|}{ Ronda } \\
\cline { 2 - 5 } & Varas & Valor (mrs) & Varas & Valor (mrs) \\
\hline Paños de Segovia & 504 & 685.440 & 273 & 408.408 \\
Baeza/Córdoba & 42.000 & 34.272 .200 & 2.166 & 1.527 .960 \\
Paños de Jaén & 42.000 & 14.280 .000 & 3.198 & 1.087 .320 \\
Bayetas Flandes & 3.600 & 1.346 .400 & & \\
Bayetas tierra & 1.200 & 408.000 & 12 piezas & 122.400 \\
Rejillas & & & 4.980 & 677.280 \\
Estameñas & & & 1.089 & 166.617 \\
Frisas & & & 12 piezas & 65.696 \\
Anascotes & & & $\mathbf{1 2 . 0 9 0}$ & $\mathbf{4 . 1 0 0 . 9 3 1}$ \\
\hline TOTAL & $\mathbf{8 9 . 3 0 4}$ & $\mathbf{5 0 . 9 9 2 . 0 4 0}$ & & \\
\hline
\end{tabular}

Fuente: AGS, diversos, leg 2.145 .

Notas: Baeza/Córdoba: paños de Baeza y Córdoba (veinticuatrenos y dieciochenos). Jaén: paños de Jaén (dieciochenos y catorcenos).

El número de varas vendidas en Ronda no incluye las bayetas de la tierra y anascotes dado que el volumen de estos tejidos se expresaba en piezas.

CUADRO 4

AFORO DE LOS PAÑOS VENDIDOS EN LACIUDAD DE GRANADA, 1614-1616

\begin{tabular}{|l|c|c|c|}
\hline TIPO DE PAÑOS & $\mathbf{N}^{\mathbf{0}}$ de paños & Aforo (mrs/paño) & Valor aforo (rs) \\
\hline Fino de Segovia & 106 & 35.000 & 109.118 \\
22no primero & 81 & 30.000 & 71.469 \\
22no segundo & 122 & 25.000 & 89.706 \\
TOTAL SEGOVIA & $\mathbf{3 0 9}$ & $\mathbf{2 7 0 . 2 9 3}$ & \\
24nos y mezclas & 2.015 & 14.000 & 829.707 \\
Blancos & 500 & 12.000 & 176.479 \\
18nos & 590 & 8.000 & 138.823 \\
14nos & 395 & 6.000 & 91.764 \\
Londres & 45 & 12.000 & 15.882 \\
Sergas y estameñas & 700 & 9.000 & 205.582 \\
Bayetas & 910 & 17.000 & 112.500 \\
Rajas & 225 & 3.000 & 206.470 \\
Frisas & 2.340 & & $\mathbf{2 . 2 8 8 . 3 8 2}$ \\
\hline TOTAL & $\mathbf{8 . 0 2 9}$ &
\end{tabular}

Fuente: AGS, diversos, leg 2145.

24nos y mezclas: paños veinticuatrenos de Baeza y mezclas; 22nos: paños veintidosenos; 18nos: paños dieciochenos de la tierra; 14nos: paños catorcenos de la tierra. 
cieciochenos y catorcenos cuyo precio oscilaba entre los 9 y los 11 rs/vara. Aparte de este producto, en Linares y Huelma también se producían veinticuatrenos, aunque de precio inferior al de los de Córdoba y Baeza vendidos en Alcalá la Real -15-16 rs/vara contra 24 rs/vara. Esto pudiera deberse a diferencias de calidad o a que, al igual que en otras áreas como el distrito de los Pedroches en Córdoba, el veinticuatreno de Linares y Huelma se vendiera en jerga para recibir las fases finales en Baeza o Úbeda.

Lo anterior sugiere la presencia de marcados contrastes en la producción y comercialización de paños en varias zonas de Castilla la Vieja y Andalucía, algo que deberá ser confirmado en investigaciones posteriores sobre estos aspectos en otras zonas de ambas regiones y Castilla la Nueva. Del análisis del Apéndice 2 y los cuadros 3 y 4 parece deducirse que los paños veinticuatrenos ocupaban en Andalucía el lugar que correspondía a los paños de Segovia en Castilla la Vieja. Sin embargo, a pesar de lo llamativo de este hecho, los motivos de la escasa presencia de los paños segovianos en las ventas de ciudades como Ronda, Jaén y Granada no están claros todavía. En su estudio sobre Córdoba, Fortea sugiere que la pequeña importancia de los géneros segovianos en la ciudad andaluza pudo deberse a que su llegada podía representar una amenaza para los productos de la pañería local, de buena calidad y en la que los mercaderes locales, bien representados en el cabildo, tenían un papel destacado. Esta posibilidad parece avalada por la oposición del ayuntamiento cordobés a una provisión real llegada en 1565 en la que se incluían las ordenanzas de Segovía para el obraje de paños ${ }^{18}$, y, a falta de un estudio sobre esta cuestión, puede conjeturarse que una causa análoga explicaría la reducida importancia de los paños segovianos en las ciudades andaluzas de los Cuadros 3 y 4.

Cualquier visión sobre las ventas de tejidos en Castilla a inicios del siglo XVII quedaría incompleta si no atendiera a las transacciones de lienzos, a cuya importancia ya nos hemos referido antes.

$\mathrm{Al}$ igual que en los paños, buena parte de los tejidos de lino que entraban en las ventas eran lienzos bastos y baratos, producidos por los campesinos para satisfacer sus necesidades. Aunque no existe, hasta donde sabemos, una monografía sobre esta actividad en la Castilla del Seiscientos, su peso parece claro. En las primeras décadas de la centuria esta manufactura avanzó en numerosas localidades de Toledo, y lo mismo sucedió en los siglos XVI y XVII en varios pueblos de la provincia de Madrid y en la comarca de Béjar a fines del XVII ${ }^{19}$.

El Apéndice 2 muestra que la elaboración de lienzos también estaba difundida en otros distritos. En varias localidades de Jaén se manufacturaban lienzos bara-

\footnotetext{
${ }^{18}$ Fortea Pérez (1981, pp. 390-391). p. 28)

9 Ringrose (1985, p. 329); López García (1998, pp. 131 y 433) y Ros Massana (1999,
} 
tos, como sucedía en Jabalquinto, Torres, Albanches, Bailén, Huelma y Baños, y el legajo 2.145 certifica que lo mismo sucedía en otros núcleos, como Villardonpardo, Escañuela, Villapalacios, Bienservida, Jódar, Lupión, Mármol, Cañete y Vilches -provincia de Jaén- y Cardela, Guadaortuna, Solera, Moclín, Montefrío y Campotéjar -en la de Granada. En cuanto a los demás distritos del Apéndice, hay menciones a la elaboración de este tejido en La Puebla de Naciados y sus lugares y en el partido de Soria, y no parece aventurado suponer que los lienzos más comunes labrados en Oropesa, Talavera la Vieja, Navalmorquende y en los partidos de Medinaceli, Gomara, El Burgo de Osma y Alfaro fueran el fruto de una producción local ${ }^{20}$.

En paralelo con lo sucedido en otras regiones como Cataluña, esta industria autóctona suministraba lienzos baratos, mientras que los de mayor calidad y precio, con los que se cubría la demanda de los grupos más acomodados, se impor$\operatorname{taban}^{21}$. J. Israel (1989, p. 65) recordó la importancia de los mercados castellanos y del Nuevo Mundo para los lienzos holandeses; en cuanto a los lienzos franceses, la historiografía del país vecino a menudo ha visto en los mercados americanos la causa del esplendor de las exportaciones de los lienzos bretones a Castilla. Sin embargo, pruebas del extendido consumo de ruanes y bretañas en ambas mesetas a lo largo del siglo XVI, detectadas por H. Casado (2001, pp. 513-14), también han puesto de relieve el papel de la demanda interna castellana, y los datos del Apéndice 2 apuntan en la dirección señalada por este autor.

Atendiendo a su origen hemos considerado extranjeros a los siguientes tipos de lienzos: angeos, bombasis, cambrais, creas, holandas, holandillas, lienzos navales y ruanes. La procedencia de cambrais, fustanes, holandas, holandillas y ruanes no plantea demasiados problemas. En cuanto al resto, según una relación de 1616 con el valor de los derechos arancelarios devengados por las entradas y salidas de tejidos en Castilla, citada por E. Fernández de Pinedo y L.M Bilbao, los lienzos navales eran importados ${ }^{22}$. A su vez, el Diccionario de Autoridades define a las creas como un lienzo originario de Lyon, mientras que los angeos se traían del oeste de Francia y los bombasis eran producidos en la ciudad holandesa de Amersfoort $^{23}$.

\footnotetext{
${ }^{20}$ Además, el legajo 2.145 también indica que ya en 1614-16 la fabricación de lienzos era importante en localidades de los partidos de Orense — Villameán, Castiñeira, Laza, Camba- y Tuy -Ponteareas-, que se suman a Mondoñedo, donde P.Saavedra ha encontrado huellas de esta actividad en las mismas fechas: véase Saavedra (1984, pp. 114-115). Además, gracias a la respuesta de Viana del Bollo sabemos que en esta localidad gallega varios comerciantes adquirían los lienzos labrados en las localidades cercanas para transportarlos a la feria de la Puebla de Sanabria, desde donde eran redistribuidos por Castilla. Sobre la lencería gallega, vid. Carmona (1990).

${ }^{21}$ Para el caso catalán, vid. Torra (2002, p. 19) y Durán Pujol (2003, p. 7).

${ }^{22}$ Bilbao y Fernández de Pinedo (1993, p. 141). La relación se encuentra en las Actas de Cortes de Castilla (A.C.C), vol XXX, p. 297 y A.C.C., vol XXXI, p. 307.

${ }^{23}$ Sobre los bombasis, vid. De Vries y Van Der Woude (1997, p. 291).
} 
Teniendo en cuenta lo anterior, el 28 por cien de los lienzos vendidos en Bailén eran importados, y el 31 por cien en la villa de Oropesa. En el partido soriano de Gomara este procentaje crecía al 41,5 por cien, mientras que en los lugares de Oropesa los lienzos foráneos representaban el 48 por cien, siendo destacables los casos de los partidos de Soria y Ágreda, donde alrededor del 67 por cien de los lienzos incluidos en las transacciones eran importados, algo que, al menos en el caso de Ágreda, debiera relacionarse con el carácter fronterizo del distrito. Lo mismo ocurría en otras áreas de frontera como Figueras, en donde la cercanía a Francia propiciaba la entrada de lienzos foráneos ${ }^{24}$.

\section{ALGUNAS NOTAS SOBRE EL CONSUMO DE TEJIDOS EN VARIAS REGIO- NES CASTELLANAS}

La posibilidad de una aproximación a los niveles de consumo de tejidos en una muestra de localidades y partidos de provincias de Castilla la Vieja y Andalucía constituye una de las ventajas de nuestra fuente. Como primer paso, se ha dividido el valor trienal de las ventas de textiles en varios partidos de las provincias de Soria, el partido de Toro y en un grupo de villas y aldeas de Ávila, Jaén y Sevilla, así como en las villas de Sepúlveda y Peñafiel, por el número de sus vecinos en 1631, indicado en el Vecindario de la Sal ${ }^{25}$.

Somos conscientes de que este tipo de ejercicios no carece de limitaciones. Por ejemplo, al dividir las ventas de tejidos del partido de Soria -o de cualquier otropor el número de vecinos del mismo en 1631 se asume que éstos fueron los únicos

${ }^{24}$ Para el caso de Figueras, vid. Torra (1997, p. 185). Nuestras estimaciones probablemente están infravaloradas porque en ellas no hemos incluido algunos productos cuyo origen ha sido imposible establecer, aunque parece probable que fueran extranjeros, como los bocacíes, bofetanes, lienzos campeos, caniquíes, manteles y melinges. De haberlo hecho, el peso de los lienzos foráneos hubiera crecido de forma notable, sobre todo en la villa de Oropesa, alcanzando el 59 por cien, y en el partido de Ágreda, donde llegaría nada menos que al 100 por cien.

${ }^{25}$ Sobre este vecindario y sus datos, vid. Piquero, Ojeda y Fernández de Pinedo (1990). Al calcular las medias correspondientes a las villas se han incluido tanto el monto de las transacciones de tejidos en sus aldeas como el número de vecinos residentes en las mismas. En Soria se han incluido los partidos de Soria, Ágreda, El Burgo de Osma, Calahorra, Atienza, Nalda y Alfaro. En la provincia de Toro sólo se ha calculado la media correspondiente al partido del mismo nombre. En cuanto a Ávila, nuestros datos proceden de la villa de Oropesa y su tierra, Talavera la Vieja, Navalmorquende y su tierra y La Puebla de Naciados. Por lo que hace a Sevilla, se han empleado los datos de las localidades del Apéndice 1, en tanto que para Jaén se ha recurrido a los de Bejíjar, Lupión, Rus, Ibros, Vilches, Baños, Jabalquinto, Torres, Albanches, Bedmar, Garcés, Linares, Villapalacios, Cotillas, Partido de Villapalacios, Villaverde, Bienservida, Bailén, El Marmolejo, Santiesteban, Huelma y Villafranca. Agradezco a S. Piquero, E. Fernández de Pinedo y R. Ojeda su cortesía por haberme facilitado los datos demográficos de estos núcleos en 1631. 
compradores de los textiles vendidos en el distrito, supuesto no exento de una cierta arbitrariedad, dado que parte de los tejidos debió ser adquirida por compradores de otros partidos de la provincia y de zonas cercanas. Sin embargo, estos problemas, bien conocidos por los historiadores, no han impedido que cálculos similares se hayan empleado desde hace tiempo para medir el consumo alimentario de poblaciones del pasado y reflejar las grandes tendencias del mismo, estableciendo comparaciones entre diversos momentos y lugares. Teniendo en cuenta estas limitaciones, pensamos que los resultados de nuestro análisis pueden ser de interés y que quizá incluso podrían apuntar líneas de investigación interesantes para el futuro ${ }^{26}$.

Según nuestras estimaciones, el valor medio de las compras trienales de tejidos en las localidades sevillanas ascendía a 6.079 mrs/vecino, y a 4.112 mrs/vecino en las jienenses. En las villas de Ávila, el valor medio de las compraventas era de 2.335 mrs/vecino, mientras que en los partidos de Soria y Toro este indicador caía hasta los 1.207 y los 910 mrs/vecino, respectivamente. Por último, en la villa de Sepúlveda el valor medio de las compras, 916 mrs/vecino, resultaba comparable al del partido de Toro, pero en la cercana villa de Peñafiel experimentaba un sensible descenso, hasta los 342 mrs/vecino, siendo el más bajo de toda la muestra.

El contraste entre los valores de las transacciones de tejidos por vecino de las localidades de Andalucía y de las villas y partidos de Castilla la Vieja resulta elocuente, y podría considerarse como un indicio de la presencia de distintos niveles de consumo de textiles en ambas zonas.

En el mismo sentido apuntan los resultados del Cuadro 5, en el que se ofrecen las relaciones de intercambio entre la fanega de trigo -precio medio- en 1614-16 en Castilla la Vieja y Andalucía, y varios paños, lienzos y tejidos de seda en algunas localidades de Jaén y en algunos partidos de Soria, villas de Ávila, así como en la ciudad de Valladolid. Los precios de la fanega de trigo se han obtenido de la obra de Hamilton, mientras que las cotizaciones de tejidos proceden del Apéndice 2 y del informe del Corregidor de Valladolid antes citado.

Por supuesto, hubiera sido conveniente haber dispuesto de precios de más tejidos y, asimismo, que éstos hubiesen procedido de otras regiones. Además, debe recordarse que los precios del trigo de Hamilton (1975, p. 156) en Castilla la Vieja para el período 1601-50 proceden de varios conventos y hospitales de León y Valladolid, y los de Andalucía del Hospital de la Sangre de Sevilla; si bien hemos decidido emplearlos, a falta de precios de la fanega de trigo en Jaén, Ávila o Soria en 161416, los resultados del Cuadro 5 poseen, por ello, un valor puramente indicativo.

${ }^{26}$ Para el caso castellano pueden verse, por ejemplo, los datos sobre el consumo de carne, vino y aceite "per capita» en la ciudad de Valladolid en el siglo XVI de Bennassar (1967, pp. 72-6), y los del XVII de Gutiérrez Alonso (1989, pp. 281-289), así como los de Madrid de Ringrose (1985, pp. 147-148). En cuanto a este último caso, puede verse también la estimación de la dieta diaria en el período 1591-1767 realizada por el Equipo Madrid de Estudios Históricos, en López García (1998, pp. 357). 
CUADRO 5

RELACIONES DE INTERCAMBIO ENTRE LA FANEGA DE TRIGO Y VARIOS TEXTILES EN ANDALUCIA Y CASTILLA LA VIEJA EN 1614-1616

\begin{tabular}{|l|c|c|c|c|}
\hline \multirow{2}{*}{} & \multicolumn{2}{|c|}{ Jaén } & \multicolumn{2}{c|}{ Castilla la Vieja } \\
\cline { 2 - 5 } & $\begin{array}{c}\text { Tejido } \\
\text { (reales) }\end{array}$ & $\begin{array}{c}\text { RI } \\
\text { (varas/fanega) }\end{array}$ & $\begin{array}{c}\text { Precio } \\
\text { (reales) }\end{array}$ & $\begin{array}{c}\text { RI } \\
\text { (varas/fanega) }\end{array}$ \\
\hline Perpetuanes & 7,15 & 2,72 & 7 & 2,24 \\
Perpetuanes* & 7,15 & 2,72 & 7 & 2,24 \\
Frisas & 3 & 6,56 & 3,5 & 4,48 \\
Frisas* & 3 & 6,56 & 3 & 5,23 \\
Estameñas & 4,5 & 4,41 & 4,25 & 3,69 \\
Anascotes & 7 & 2,82 & 6 & 2,5 \\
Tafetanes & 8,12 & 2,42 & 6,84 & 2,29 \\
Tafetanes* & 8,12 & 2,42 & 8 & 1,96 \\
Pasamanos & 73,7 & $0,27(l i / f a n)$ & 65,7 & 0,24 (li/fan) \\
Listones & 0,47 & 42 & 0,66 & 23,7 \\
Terciopelos & 32,5 & 0,6 & 42 & 0,37 \\
Terciopelos* & 32,5 & 0,6 & 34 & 0,46 \\
Angeos & 2,5 & 7,92 & 2,4 & 6,54 \\
Holandas & 9 & 2,20 & 9 & 1,74 \\
Holandas* & 9 & 2,20 & 8 & 1,96 \\
Creas & 3 & 6,6 & 2 & 7,85 \\
Fustanes & 3 & 6,6 & 2,5 & 6,28 \\
Telillas & 4 & 4,95 & 2,5 & 4 \\
Bofetanes* & 3,51 & 5,65 & 6,28 \\
\hline
\end{tabular}

Fuentes: Apéndice 2. Para los precios del trigo en Andalucía (19,7 reales/fananega) y en Castilla la Vieja (15,7 reales/fanega), Hamilton (1975, pp. 379 y 397).

Nota: * Precio del tejido en Valladolid, según el informe de su corregidor.

Hechas estas salvedades, el cuadro refleja un contraste entre las localidades de Jaén y los partidos y villas de Castilla la Vieja. Con la excepción de las creas y los bofetanes, en el resto de los casos la relación de intercambio resultaba más favorable al trigo en las localidades de Jaén que en los distritos de Castilla la Vieja. Con una fanega de trigo se compraban más varas de, por ejemplo, perpetuanes, terciopelos u holandas en Bailén y Linares que en Oropesa o El Burgo de Osma, de modo que, en términos relativos, los tejidos eran más baratos en las villas y lugares jienenses.

Esto puede explicarse atendiendo a dos factores. Por un lado, conforme a lo señalado por la historiografía tradicional, los precios de los tejidos del Apéndice 2 eran más elevados en las villas y aldeas de Jaén que en los distritos de Castilla la Vieja, pero merece la pena destacar que las diferencias en las cotizaciones no eran excesivas -e incluso había casos como el de los listones o terciopelos, más caros en Ávila y Soria que en Jaén. Por el otro, el precio medio de la fanega de 
trigo en Castilla la Vieja en 1614-16 -15,7 reales-) fue más reducido que en Andalucía -19,7 reales.

Este último aspecto posee un interés especial porque permite plantear, a modo de hipótesis que deberá ser confirmada en investigaciones futuras, algunos elementos que pueden ayudar a un mejor conocimiento de las dificultades de la pañería castellana y, en especial, segoviana en las primeras décadas del siglo XVII.

Aunque la crisis también afectó a las industrias textiles de otras ciudades, la historiografía ha mostrado un marcado interés por la decadencia de la pañería segoviana. Los paños de la ciudad castellana eran consumidos, como ya se ha indicado, por las clases medias y acomodadas de las ciudades del interior, muy perjudicadas por la crisis del XVII a causa de las dificultades padecidas en sus principales fuentes de ingresos, como eran los juros, las rentas fijas en dinero obtenidas del desempeño de cargos en la administración local y real, y las rentas del suelo. Los problemas de los juros y las rentas monetarias procedentes de puestos burocráticos son bien conocidos. En cuanto a la renta del suelo, en varias áreas de de la Meseta Norte ya había comenzado a caer en las últimas décadas del siglo $\mathrm{XVI}^{27}$. A esto habría que sumar el hecho de que los precios del trigo de Castilla la Vieja fueran más reducidos que los de Andalucía, algo debido no sólo al tradicional desnivel de precios entre ambas regiones sino también, según Hamilton, a los efectos de la crisis demográfica ${ }^{28}$. Todo esto hacía que la capacidad de adquirir tejidos de aquellos sectores de la región en cuyas fuentes de ingresos la percepción de rentas del suelo en especie tuviera un valor destacado fuera probablemente menor que la de sus colegas de Andalucía, donde, por otro lado, parece posible que la producción agrícola, y con ella las rentas del suelo y los precios, aguantaran mejor en las primeras décadas del siglo XVII ${ }^{29}$.

De ser cierto lo anterior, se podría explicar que las relaciones de intercambio entre la fanega de trigo y los textiles resultasen más favorables en Jaén que en los partidos de Soria y en las villas de Ávila y Valladolid, lo que sugiere que el consumo de tejidos

\footnotetext{
${ }^{27}$ El descenso de la renta comenzó en tierras de Segovia y Zamora a fines del XVI, según muestran García Sanz (1977, pp. 304 ss.) y Álvarez Vázquez (1987, apéndice II, pp. 416-39). A su vez, aunque con excepciones locales, F. Brumont (1993, pp. 307-311) también detecta un notable y rápido descenso de la renta del suelo en la parte oriental de Burgos, en La Rioja y en áreas de la Tierra de Campos en las décadas finales del Quinientos. En otras comarcas de la misma región el inicio de la caída se retrasó algo, como sucedió en varias tierras del hospital de San Antolín estudiadas por Marcos Martín (1985, vol. 1, p. 211), en donde la subida de las rentas se prolongó en las dos primeras décadas del XVII, aunque luego se inició el descenso.

${ }^{28}$ Véase Hamilton (1975, p. 256). Además, Hamilton también apunta a la tasa del trigo como otra causa del retraso de los precios de este producto en Castilla la Vieja respecto de Andalucía.

${ }^{29}$ A. García Sanz (1989, pp. 171-172) planteó la posibilidad de que Andalucía estuviera a cubierto de la depresión agraria, al menos por lo que toca a la variable producción. Esta conclusión es similar a la formulada por A. Marcos Martín (2000, p. 477).
} 
debía de ser mayor en la provincia andaluza ${ }^{30}$. Si recordamos que los valores de las compras de textiles por vecino también eran mayores en las localidades de Jaén y Sevilla que en los partidos de Castilla la Vieja del Apéndice 2, y si admitimos la representatividad de estos datos, parece dibujarse una clara diferencia entre los niveles de consumo de tejidos en Andalucía y Castilla la Vieja en beneficio de la primera.

La posibilidad de incrementar sus ventas en los mercados andaluces pudo ser, al menos en teoría, una de las salidas consideradas por los productores segovianos para compensar los problemas sufridos por la contracción de los tradicionales mercados de Castilla la Vieja. Sin embargo, ya se ha indicado en el apartado anterior la escasa importancia de los paños segovianos en las ciudades de Jaén, Granada y Ronda. Si investigaciones futuras sobre otras ciudades andaluzas confirmaran esta imagen, podría alegarse que, entre los elementos que explican las dificultades de la pañería segoviana, habría que citar los problemas de los tradicionales consumidores de los mercados de Castilla la Vieja, acentuados por las dificultades de acceso de los productos segovianos a otros mercados con mayor capacidad de demanda, como las ciudades andaluzas.

Por otro lado, merece la pena recordar que esta hipótesis parece consistente con lo que sabemos acerca de la historia económica castellana a lo largo del período. Según nuestras investigaciones sobre la fiscalidad castellana, niveles de consumo de vino, vinagre, carne y aceite, más reducidos en Castilla la Vieja que en Andalucía fueron una de las causas del alza de la participación andaluza en los pagos del servicio de millones entre 1601 y 1639. Si a esto añadimos que la gravedad de los problemas demográficos en Castilla la Vieja a inicios del XVII está bien comprobada, pensamos que, tomados en conjunto, todos estos elementos constituyen un elocuente reflejo de la grave crisis sufrida por dicha región en el período ${ }^{31}$.

\footnotetext{
${ }^{30}$ Por supuesto, de esta ventaja se beneficiarían, sobre todo, aquellos sectores de la región en cuyas fuentes de ingresos la percepción de rentas del suelo en especie tuviera importancia. Estos grupos podrían acceder al consumo de textiles de buena calidad y precio elevado, mientras que para el resto de la población el recurso a los textiles más bastos y baratos, en la mayor parte de los casos fabricados localmente para satisfacer sus propias necesidades, sería la norma. Se puede conjeturar que este último grupo debió crecer a lo largo del siglo XVII, según se desprende del avance de la figura del jornalero en la Andalucía Occidental y en áreas de la Oriental, como Jaén, constatado por A. M. Bernal (1981, p. 223) y por J. Rodríguez Molina (1981, p. 317), respectivamente.

${ }^{31}$ Entre 1601 y 1635, el aporte andaluz a los pagos de millones creció del 31 por cien al 46,7 por cien. En el mismo plazo, el peso de Castilla la Vieja descendió desde el 49 por cien al 26 por cien: vid. Andrés Ucendo (1999, p. 167). En cuanto a la trayectoria de la población, según el análisis de S. Piquero, R. Ojeda y E. Fernández de Pinedo (1991, p. 84, nota 16), basado en una muestra de los partidos de las salinas de la Corona de Castilla, el tamaño de la población de una muestra de distritos de la Meseta Norte se redujo desde un índice 100 en 1591 a 52 en 1631, mientras que la de la Meseta Sur cayó a 87 y la de Andalucía incluso experimentó una ligera alza. Aunque las muestras de la Meseta Sur y Andalucía estudiadas por estos autores no son tan completas como las de la Meseta Norte, estos datos pueden considerarse representativos del comportamiento global de la población entre 1591 y 1631 .
} 


\section{CONCLUSIONES}

Las páginas anteriores revelan notables contrastes en la comercialización de textiles en una muestra de partidos y villas de Castilla la Vieja y Andalucía en 1614-16. Los paños eran los tejidos más vendidos, aunque se percibe una clara diferencia entre los distritos de Castilla la Vieja del Apéndice 1, Guadalajara y Jaén, donde los tejidos de lana eran los más destacados, y Sevilla, donde este lugar lo ocupaban los lienzos.

Las investigaciones de las pasadas décadas han puesto de relieve el peso de los lienzos en las ventas de tejidos en Castilla y Cataluña durante el siglo XVIII, y los cuadros 1 y 2 dejan pocas dudas acerca de la innegable importancia de este tejido en 1614-16. No es éste el único parecido con Cataluña. Al igual que en el Principado, el documento revela la existencia de una industria muy difundida dedicada a la confección de lienzos bastos para el autoconsumo, mientras que los de mayor calidad se importaban, siendo reseñable el peso de las importaciones en áreas fronterizas como Ágreda.

En cuanto a los paños, la estructura de sus ventas se caracteriza por rasgos tradicionales, gestados a lo largo de la expansión del siglo XVI. Dentro del segmento de paños de calidad media y alta, los paños segovianos y andaluces gozaban de una posición de privilegio. Los primeros se vendían en las ciudades y villas de la Meseta Norte de los apéndices 1 y 2 y, aunque no fueran desconocidos en las andaluzas, los cuadros 3 y 4 sugieren que su presencia en las mismas debía de ser reducida a causa de la hegemonía de los paños veinticuatrenos.

Por último, si admitimos la representatividad de nuestros datos, del análisis de indicadores como los valores de las compraventas de tejidos por vecino y las relaciones de intercambio entre la fanega de trigo y varios tejidos parece desprenderse que el consumo de textiles era más elevado en Andalucía que en la Meseta Norte. Esto permite plantear una hipótesis que habrá que verificar en futuras investgaciones y que puede ayudar a explicar las dificultades de la pañería segoviana atendiendo a factores del lado de la demanda. Los niveles de consumo de textiles menos elevados en las villas y partidos de Castilla la Vieja del Apéndice 2 a inicios del siglo XVII indicarían un estrechamiento de uno de los tradicionales mercados de este producto $\mathrm{y}$, a causa de su reducido peso en las ventas de ciudades como Jaén, Ronda o Granada, parece muy posible que los productores de la ciudad castellana no pudieran compensar tales dificultades incrementando sus ventas en las ciudades andaluzas, donde los niveles de consumo de textiles debían de ser más elevados. 


\section{BIBLIOGRAFÍA}

Actas de las Cortes de Castilla. (1861) Madrid: Sucesores de Rivadeneyra.

Álvarez VÁzquez, J. A. (1987): Rentas, precios y crédito en Zamora en el Antiguo Régimen. Zamora: Colegio Universitario.

Andrés Ucendo, J. I. (1999): La fiscalidad en Castilla en el siglo XVII: Los servicios de millones, 1601-1700. Bilbao/Lejona: Universidad del País Vasco.

Bennassar, B. (1967): Valladolid au siècle d'Or. Une ville de Castille et sa campagne au XVIe siècle. París-La Haya: Mouton.

Bernal, A. M. (1981): «Andalucía Occidental. Economía rural, 1590-1765», en Historia de Andalucía. Barcelona: Planeta, vol. VI, pp. 185-242.

Bernal, A. M., Collantes de Terán, A. y García Baquero, A. (1978): «Sevilla: de los gremios a la industrialización». Estudios de Historia Social (5-6), pp. 7-307.

Bernis, C. (2001): El traje y los tipos sociales en el Quijote. Madrid: El Viso.

Bilbao, L. M. y FernáNDEZ DE PINEdo, E. (1993): «Artesanía e Industria», en Miguel Artola (ed.), Enciclopedia de Historia de España, vol 1, Economía. Sociedad. Madrid: Alianza, pp. 105-190.

Brumont, F. (1993): Paysans de Vieille Castille aux XVI et XVIIe siècles. Madrid: CNRS.

Carande, R. (1990): Carlos V y sus banqueros. Barcelona: Crítica.

Carmona, X. (1990): El atraso industrial de Galicia. Auge y decadencia de las manufacturas textiles, 1750-1900. Barcelona: Ariel.

Casado Alonso, H. (1990): «El comercio del pastel. Datos para una geografía de la industria pañera española en el siglo XVI». Revista de Historia Económica VIII (3), pp. 523-545.

- (2001), «Medina del Campo Fairs and The Integration of Castile into $15^{\text {th }}$ to $16^{\text {th }}$ Century European Economy», en Fiere e mercati nella integrazione delle economie europee secc. XIII-XVIII. Serie II. Atti delle Settimane di Studi. Instituto Internazionale di Storia Economica F. Datini. Florencia: Le Monnier, pp. 495-517.

De VRIES, J. (1994): «The Industrial Revolution and the Industrious Revolution». Journal of Economic History 54, pp. 249-70.

De VRies, J. y Van der Woude, A. (1997): The first modern economy. Cambridge: Cambridge University Press.

Durán Pujol, M. (2003): «Oferta y consumo de tejidos en Cataluña en la segunda mitad del siglo XVII», en E. Llopis, J. Torras y B. Yun (eds.), El consumo en la España preindustrial. Madrid: Marcial Pons / Centro de Estudios Políticos y Constitucionales / Caja Madrid, pp. 61-87.

Fortea Pérez, J. I. (1981): Córdoba en el siglo XVI: las bases demográficas y económicas de una expansión urbana. Córdoba: Publicaciones del Monte de Piedad y Caja de Ahorros de Córdoba.

García Sanz, A. (1977): Desarrollo y crisis del Antiguo Régimen en Castilla la Vieja. Economía y sociedad en tierras de Segovia, 1500-1814, Madrid: Akal.

- (1989): «El sector agrario durante el siglo XVII: depresión y reajustes», en Historia de España de Menéndez de Pidal. Madrid: Espasa, vol. XXIII, pp. 161-238.

— (1990): «Población e industria textil en una ciudad de Castilla: Segovia, 1530-1750», en J. Nadal (coord.), La evolución demográfica bajo los Austrias. Alicante: Instituto de Cultura Juan Gil Albert, pp. 153-168. 
Garzón Pareja, M. (1972): La industria sedera en España. El arte de la seda en Granada. Granada: Archivo de la Real Chancillería.

Gutiérrez Alonso, A. (1989): Estudio sobre la decadencia de Castilla. La ciudad de Valladolid en el siglo XVII. Valladolid: Universidad de Valladolid.

Hamilton, E. (1975): El Tesoro Americano y la revolución de los precios en España. Barcelona: Ariel.

Hoyo Aparicio, A. y Maruri Villanueva, R. (2003): «Pautas de consumo textil en una sociedad rural: Liébana (Cantabria), 1700-1860», en E. Llopis, J. Torras y B. Yun (eds.), El consumo en la España pre-industrial. Madrid: Marcial Pons / Centro de Estudios Políticos y Constitucionales / Caja Madrid, pp. 107-140.

IRADIEL, P. (1974): Evolución de la industria textil castellana en los siglos XIII al XVI. Salamanca: Universidad de Salamanca.

Israel, J. (1989): Dutch Primacy in the World Trade. Oxford: Oxford University Press.

López García, J. M. (dir.) (1998): El impacto de la Corte en Castilla. Madrid y su territorio en la época moderna. Madrid: Siglo XXI de España.

Marcos Martín, A. (1985): Economía, sociedad, pobreza en Castilla: Palencia, 1500-1814. Palencia: Diputación de Palencia, 2 vols..

- (2000): España en los siglos XVI, XVII y XVIII. Economía y sociedad. Barcelona: Crítica / Caja Duero.

Miralles, P. (2002): La sociedad de la seda. Murcia: Universidad de Murcia.

Montemayor, J. (1996): Tolède entre fortune et déclin, 1530-1640. Limoges: PULIM, D.L.

Piquero, S., Ojeda, R. y Fernández de Pinedo, E. (1991): «El Vecindario de 1631. Presentación y primeros resultados», en J. Nadal (coord.), La evolución demográfica bajo los Austrias. Alicante: Instituto de Cultura Juan Gil Albert, pp. 77-97.

Ramos Palencia, F. C. (2003): «La demanda de textiles en las familias castellanas a finales del Antiguo Régimen, 1750-1850: ¿Aumento del consumo sin industrialización?», en E. Llopis, J. Torras y B. Yun (eds.), El consumo en la España pre-industrial. Madrid: Marcial Pons / Centro de Estudios Políticos y Constitucionales / Caja Madrid, pp. 141-180.

Real Academia Española: Diccionario de Autoridades (1963) [1726]. Madrid: Gredos. Edición facsímil.

Ringrose, D. (1985): Madrid y la economía española, 1560-1850. Madrid: Alianza.

RodríGuez Molina, J. (1981). «Demografía, sociedad y economía en Jaén, 1621-1778», en Historia de Andalucía. Barcelona: Planeta, vol. VI, pp. 289-328.

Ros Massana, R. (1999): La industria textil lanera de Béjar, 1680-1850, en E. Llopis, J. Torras y B. Yun (eds.), El consumo en la España pre-industrial. Madrid: Marcial Pons / Centro de Estudios Políticos y Constitucionales / Caja Madrid, pp. 21-37.

Ruiz Martín, F. (1965): «La empresa capitalista y la industria textil castellana durante los siglos XVI y XVII», en Third International Conference of Economic History. MunichParís: Mouton, pp. 267-276.

- (1966): «Un testimonio literario sobre las manufacturas de paños de Segovia», en $\mathrm{Ho}$ menaje al Profesor Alarcos García. Valladolid: Universidad de Valladolid / Junta de Castilla y León.

SAavedra, P. (1983): «Desarrollo y crisis de la industria textil gallega. El ejemplo de la lencería, 1600-1840». Cuadernos de Investigación Histórica (7), pp. 113-132.

Torra FERnÁndez, L. (1997): «Comercialización y consumo de tejidos en Cataluña, (16501800)», Revista de Historia Industrial (11), pp. 177-195. 
— (2002): «Cambios en la oferta y la demanda textil en Barcelona, (1650-1800)». Revista de Historia Industrial (22), pp. 13-43.

- (2003), «Las botigues de teles de Barcelona: aportación al estudio de la oferta de tejidos y del crédito al consumo, 1650-1800», en E. Llopis, J. Torras y B. Yun (eds.), El consumo en la España pre-industrial. Madrid: Madrid: Marcial Pons / Centro de Estudios Políticos y Constitucionales / Caja Madrid, pp. 89-105.

VAN Zanden, J. L. (1999): «Wages and the standard of living in Europe, 1500-1800», European Review of Economic History 3 (2), pp. 175-197.

— (2002): «The «revolt of the early modernists» and «The first modern economy»: an assesment». Economic History Review LV (4), pp. 619-41.

Weisser, M. (1971): «Les marchands de Tolède dans l'économie castillane, 1565-1635». Mélanges de la Casa de Velázquez (7), pp. 223-236.

- (1973): «The Decline of Castile Revisited: the Case of Toledo», Journal of European Economic History (2), pp. 614-640.

Yun, B. y ToRrRas, J. (1999): Consumo, condiciones de vida y comercialización: Cataluña y Castilla, siglos XVII y XVIII. Valladolid: Junta de Castilla y León.

\section{APÉNDICE 1:}

VALOR MONETARIO DE LAS VENTAS DE TEJIDOS EN CASTILLA, 1614-1616 (MARAVEDÍS)

CUADRO A1-1

LUGARES DE LA PROVINCIA DE SEVILLA

\begin{tabular}{|l|r|r|r|r|}
\hline \multicolumn{1}{|c|}{ Nombre } & \multicolumn{1}{c|}{ Paños } & Tejidos de seda & \multicolumn{1}{c|}{ Lienzos } & \multicolumn{1}{c|}{ Total } \\
\hline Écija & 6.847 .668 & 4.341 .630 & 17.732 .700 & 28.921 .998 \\
Cádiz & 10.500 .000 & 10.500 .000 & 10.500 .000 & 31.500 .000 \\
Carmona & 8.235 .480 & 5.113 .500 & 10.200 .000 & 23.548 .980 \\
Marchena & 2.805 .000 & 326.400 & 2.418 .000 & 5.549 .400 \\
Lora & 651.984 & - & 37.332 & 689.316 \\
Teba & 823.410 & 26.180 & 859.290 & 1.708 .880 \\
Fuentes & 658.308 & 78.580 & 532.848 & 1.269 .736 \\
Alcolea & 20.400 & 14.688 & - & 35.088 \\
Tocina & - & 22.848 & 306.000 & 328.848 \\
Cantillana & 820.860 & 190.794 & 290.388 & 1.302 .042 \\
Villaverde & 211.890 & 3.738 & 170.478 & 386.106 \\
Brene & 130.152 & - & 27.540 & 157.692 \\
Estepa & 3.150 .912 & 487.152 & 2.847 .126 & 6.485 .190 \\
\hline TOTAL & $\mathbf{3 4 . 8 5 6 . 0 6 4}$ & $\mathbf{2 1 . 1 0 5 . 5 1 0}$ & $\mathbf{4 5 . 9 2 1 . 7 0 2}$ & $\mathbf{1 0 1 . 8 8 3 . 2 7 6}$ \\
\hline
\end{tabular}


CUADRO A1-2

LUGARES DE LA PROVINCIA DE JAÉN

\begin{tabular}{|l|r|r|r|r|}
\hline \multicolumn{1}{|c|}{ Nombre } & Paños & Tejidos de seda & Lienzos & \multicolumn{1}{c|}{ Total } \\
\hline Bejíjar & 561.000 & 93.750 & 150.000 & 804.750 \\
Lupión & 56.100 & 8.976 & 24.660 & 89.736 \\
Rustre & 562.500 & 37.500 & 112.500 & 712.500 \\
Ibros & 225.300 & 22.500 & 75.000 & 322.800 \\
Vilches & 265.000 & 112.500 & 188.500 & 566.000 \\
Baños & 1.122 .000 & 138.750 & 255.000 & 1.515 .750 \\
Jabalquinto & 561.000 & 18.802 & 112.200 & 692.002 \\
Torres & 1.122 .000 & 112.574 & 408.000 & 1.642 .574 \\
Albanches & 336.600 & 37.366 & 122.400 & 496.366 \\
Bedmar & 1.122 .000 & 89.964 & 204.000 & 1.415 .964 \\
Garcés & 22.440 & 1.190 & 6.800 & 30.430 \\
Linares & 1.656 .480 & 217.260 & 816.000 & 2.689 .740 \\
Villapalacios & 408.000 & - & 255.000 & 663.000 \\
Cotillas & 61.200 & 10.234 & 42.840 & 114.274 \\
Partido Villapalacioss & 428.400 & 11.850 & 20.400 & 460.650 \\
Villaverde & 95.200 & - & 48.000 & 143.200 \\
Bienservida & 1.125 .000 & 24.480 & 285.600 & 1.435 .080 \\
Bailén & 2.562 .954 & 1.958 .196 & 861.900 & 5.383 .050 \\
El Marmolejo & 323.000 & 22.950 & 459.000 & 804.950 \\
Santiesteban & 225.000 & 33.600 & 102.000 & 360.600 \\
Huelma & 6.591 .036 & 499.222 & 443.700 & 7.533 .958 \\
Villafranca & 1.411 .680 & 140.352 & 91.800 & 1.643 .832 \\
Alcalá la Real & 1.160 .165 & 305.324 & 336.600 & 1.802 .089 \\
\hline TOTAL & $\mathbf{2 2 . 0 0 4 . 0 5 5}$ & $\mathbf{3 . 8 9 7 . 3 4 0}$ & $\mathbf{5 . 4 2 1 . 9 0 0}$ & $\mathbf{3 1 . 3 2 3 . 2 9 5}$ \\
\hline
\end{tabular}

CUADRO A1-3

LUGARES DE LA PROVINCIA DE GRANADA

\begin{tabular}{|l|r|r|r|r|}
\hline \multicolumn{1}{|c|}{ Nombre } & \multicolumn{1}{c|}{ Lana } & Tejidos de seda & Lienzos & \multicolumn{1}{c|}{ Total } \\
\hline Cardela & 35.700 & - & 16.575 & 52.275 \\
Meiras & 980.900 & 129.310 & 20.400 & 1.130 .610 \\
Campotéjar & 86.700 & - & 4.250 & 90.950 \\
Motril & 573.750 & 459.900 & 1.125 .000 & 2.158 .650 \\
Alhama & 1.125 .000 & 31.500 & 1.125 .000 & 2.281 .500 \\
Guadix & 2.379 .000 & 322.320 & 341.700 & 3.043 .020 \\
Calahorra & - & 1.326 & 6.426 & 7.752 \\
Serón & 306.000 & 102.000 & 20.400 & 428.400 \\
Tirgo & - & 10.200 & 20.400 & 30.600 \\
Las Cuevas & 112.608 & 5.100 & 10.200 & 127.908 \\
Vera & 168.300 & 126.990 & 306.000 & 601.290 \\
Málaga & 1.350 .000 & - & 1.125 .000 & 2.475 .000 \\
Vélez & 1.125 .000 & - & 306.000 & 1.431 .000 \\
Ronda & 3.203 .331 & 1.530 .000 & 3.426 .900 & 8.154 .231 \\
Marbella & 136.000 & 170.000 & 374.000 & 680.000 \\
\hline TOTAL & $\mathbf{1 1 . 5 8 2 . 2 8 9}$ & $\mathbf{2 . 8 8 8 . 6 4 6}$ & $\mathbf{8 . 2 2 2 . 2 5 1}$ & $\mathbf{2 2 . 6 9 3 . 1 8 6}$ \\
\hline
\end{tabular}


CUADRO A1-4

LUGARES DE LA PROVINCIA DE ZAMORA

\begin{tabular}{|c|c|c|c|c|}
\hline Nombre & Lana & Tejidos de seda & Lienzos & Total \\
\hline Zamora & 8.058 .000 & 2.978 .400 & 1.887 .000 & 12.923 .400 \\
\hline Pontevedra & 2.895 .780 & 242.352 & 15.708 & 3.153 .840 \\
\hline Betanzos & 3.468 .000 & 306.000 & 214.200 & 3.988 .200 \\
\hline Salvatierra & 153.000 & - & - & 153.000 \\
\hline Creciente & 1.346 .400 & 17.952 & 1.958 .400 & 3.322 .752 \\
\hline Alariz & 612.000 & 88.740 & 102.000 & 802.740 \\
\hline Ribadavia & 6.732 .000 & 1.030 .200 & 306.000 & 8.068 .200 \\
\hline Verín & 1.020 .000 & 81.600 & 408.000 & 1.509 .600 \\
\hline Ginzo & 225.000 & 22.500 & 180.000 & 427.500 \\
\hline Castrocavado & 30.600 & - & 20.400 & 51.000 \\
\hline Avión & - & - & 30.600 & 30.600 \\
\hline Graices & - & - & 36.720 & 36.720 \\
\hline Rubillón & - & - & 2.040 & 2.040 \\
\hline Riocaldo & - & - & 4.590 & 4.590 \\
\hline Maside & 204.000 & - & - & 204.000 \\
\hline Camba & - & - & 10.404 & 10.404 \\
\hline Castelo & 336.600 & 20.400 & 20.400 & 377.400 \\
\hline Laza & - & - & 89.760 & 89.760 \\
\hline Otero & - & - & 11.424 & 11.424 \\
\hline Castiñeira & - & - & 17.238 & 17.238 \\
\hline San Bermudo & 150.813 & - & 634.926 & 785.739 \\
\hline Arderius & - & 8.976 & 22.440 & 31.416 \\
\hline Araujo & - & 4.488 & 22.440 & 26.928 \\
\hline Sarria & 128.520 & 10.812 & - & 139.332 \\
\hline Villalba & 1.285 .200 & 78.336 & 65.280 & 1.428 .816 \\
\hline Neyra & 56.100 & 30.600 & 61.200 & 147.900 \\
\hline Parga & 2.244 .000 & 112.200 & - & 2.356 .200 \\
\hline Barón & 1.224 .000 & 77.520 & 387.090 & 1.688 .610 \\
\hline Puerto Marín & 1.122 .000 & 204.000 & 224.000 & 1.550 .000 \\
\hline TOTAL & 31.292 .013 & 5.315 .076 & 6.732 .260 & 43.339 .349 \\
\hline
\end{tabular}




\section{CUADRO A1-5}

PARTIDOS DE LA PROVINCIA DE TORO

\begin{tabular}{|l|r|r|r|r|}
\hline \multicolumn{1}{|c|}{ Nombre } & \multicolumn{1}{c|}{ Lana } & Tejidos de seda & Lienzos & \multicolumn{1}{c|}{ Total } \\
\hline Toro & 2.193 .000 & 267.648 & 1.224 .000 & 3.684 .648 \\
Carrión & 2.436 .780 & 276.420 & - & 2.713 .200 \\
Becerril & 559.572 & 164.220 & 387.600 & 1.111 .392 \\
\hline TOTAL & $\mathbf{5 . 1 8 9 . 3 5 2}$ & $\mathbf{7 0 8 . 2 8 8}$ & $\mathbf{1 . 6 1 1 . 6 0 0}$ & $\mathbf{7 . 5 0 9 . 2 4 0}$ \\
\hline
\end{tabular}

\section{CUADRO A1-6}

PARTIDOS DE LA PROVINCIA DE SORIA

\begin{tabular}{|l|r|r|r|r|}
\hline \multicolumn{1}{|c|}{ Nombre } & \multicolumn{1}{c|}{ Lana } & Tejidos de seda & \multicolumn{1}{c|}{ Lienzos } & \multicolumn{1}{c|}{ Total } \\
\hline Soria & 2.612 .928 & 668.114 & 338.980 & 3.620 .052 \\
Ágreda & 478.380 & 115.260 & 591.756 & 1.185 .396 \\
El Burgo de Osma & 1.182 .588 & 83.980 & 117.810 & 1.384 .378 \\
Medinaceli & 660.960 & 36.108 & 36.720 & 733.788 \\
Atienza & 169.014 & 52.972 & 541.518 & 763.504 \\
Calahorra & 1.526 .794 & 271.114 & 267.884 & 2.065 .792 \\
Nalda & 238.000 & 294.400 & 86.360 & 618.760 \\
Alfaro & 2.158 .320 & 87.142 & 19.584 & 2.265 .046 \\
Gomara & - & 9.792 & 103.122 & 112.914 \\
\hline TOTAL & $\mathbf{9 . 0 2 6 . 9 8 4}$ & $\mathbf{1 . 6 1 8 . 9 1 2}$ & $\mathbf{2 . 1 0 3 . 7 3 4}$ & $\mathbf{1 2 . 7 4 9 . 6 3 0}$ \\
\hline
\end{tabular}

CUADRO A1-7

LUGARES DE LA PROVINCIA DE LEÓN

\begin{tabular}{|l|r|r|r|r|}
\hline \multicolumn{1}{|c|}{ Nombre } & \multicolumn{1}{|c|}{ Lana } & Tejidos de seda & \multicolumn{1}{c|}{ Lienzos } & \multicolumn{1}{c|}{ Total } \\
\hline León & 6.093 .852 & 1.626 .076 & 948.937 & 8.668 .865 \\
Cacabelos & 672.000 & - & 61.200 & 733.200 \\
Bembibre & - & - & 306.000 & 306.000 \\
Cangas de Tineo & 3.937 .500 & - & 225.000 & 4.162 .500 \\
La Bañeza & 775.104 & 249.873 & 78.987 & 1.103 .964 \\
Sahagún & 232.650 & 50.598 & - & 283.248 \\
Valderas & 2.037 .348 & 67.728 & 292.599 & 2.397 .675 \\
Astorga & 304.635 & 120.912 & 42.663 & 468.210 \\
Villamán & - & 9.810 & - & 9.810 \\
\hline TOTAL & $\mathbf{1 4 . 0 5 3 . 0 8 9}$ & $\mathbf{2 . 1 2 4 . 9 9 7}$ & $\mathbf{1 . 9 5 5 . 3 8 6}$ & $\mathbf{1 8 . 1 3 3 . 4 7 2}$ \\
\hline
\end{tabular}


CUADRO A1-8

LUGARES DE LA PROVINCIA DE ÁVILA

\begin{tabular}{|l|r|r|r|r|}
\hline \multicolumn{1}{|c|}{ Nombre } & Lana & \multicolumn{1}{c|}{$\begin{array}{c}\text { Tejidos } \\
\text { de seda }\end{array}$} & Lienzos & \multicolumn{1}{c|}{ Total } \\
\hline Oropesa & 573.471 & 170.584 & 227.596 & 971.651 \\
Tierra de Oropesa & 3.655 .068 & 81.696 & 105.315 & 3.842 .079 \\
Talavera la Vieja & 336.600 & 21.522 & 76.500 & 434.622 \\
Navalmorquende & 81.073 & 10.574 & 32.742 & 124.389 \\
Tierra Navalmorquende & 30.872 & - & 19.992 & 50.864 \\
La Puebla de Naciados & - & - & 28.050 & 28.050 \\
Tierra de La Puebla & 505.512 & - & 369.750 & 875.262 \\
\hline TOTAL & $\mathbf{5 . 1 8 2 . 5 9 6}$ & $\mathbf{2 8 4 . 3 7 6}$ & $\mathbf{8 5 9 . 9 4 5}$ & $\mathbf{6 . 3 2 6 . 9 1 7}$ \\
\hline
\end{tabular}

\section{CUADRO A1-9}

LUGARES DE LA PROVINCIA DE SEGOVIA

\begin{tabular}{|c|c|c|c|c|}
\hline Nombre & Lana & Tejidos de seda & Lienzos & Total \\
\hline Sepúlveda & 1.346 .400 & 43.350 & 178.500 & 1.568 .250 \\
\hline
\end{tabular}

CUADRO A1-10

LUGARES DE LA PROVINCIA DE VALLADOLID

\begin{tabular}{|c|c|c|c|c|}
\hline Nombre & Lana & Tejidos de seda & Lienzos & Total \\
\hline Peñafiel & 307.020 & 116.859 & 25.368 & 449.247 \\
\hline
\end{tabular}

CUADRO A1-11

PROVINCIA DE GUADALAJARA

\begin{tabular}{|c|c|c|c|c|}
\hline Nombre & Lana & Tejidos de seda & Lienzos & Total \\
\hline Provincia Guadalajara & 27.982 .884 & 4.780 .842 & 3.774 .476 & 36.538 .202 \\
\hline
\end{tabular}


CONSUMO Y COMERCIALIZACIÓN DE TEJIDOS EN CASTILLA, SIGLO XVII

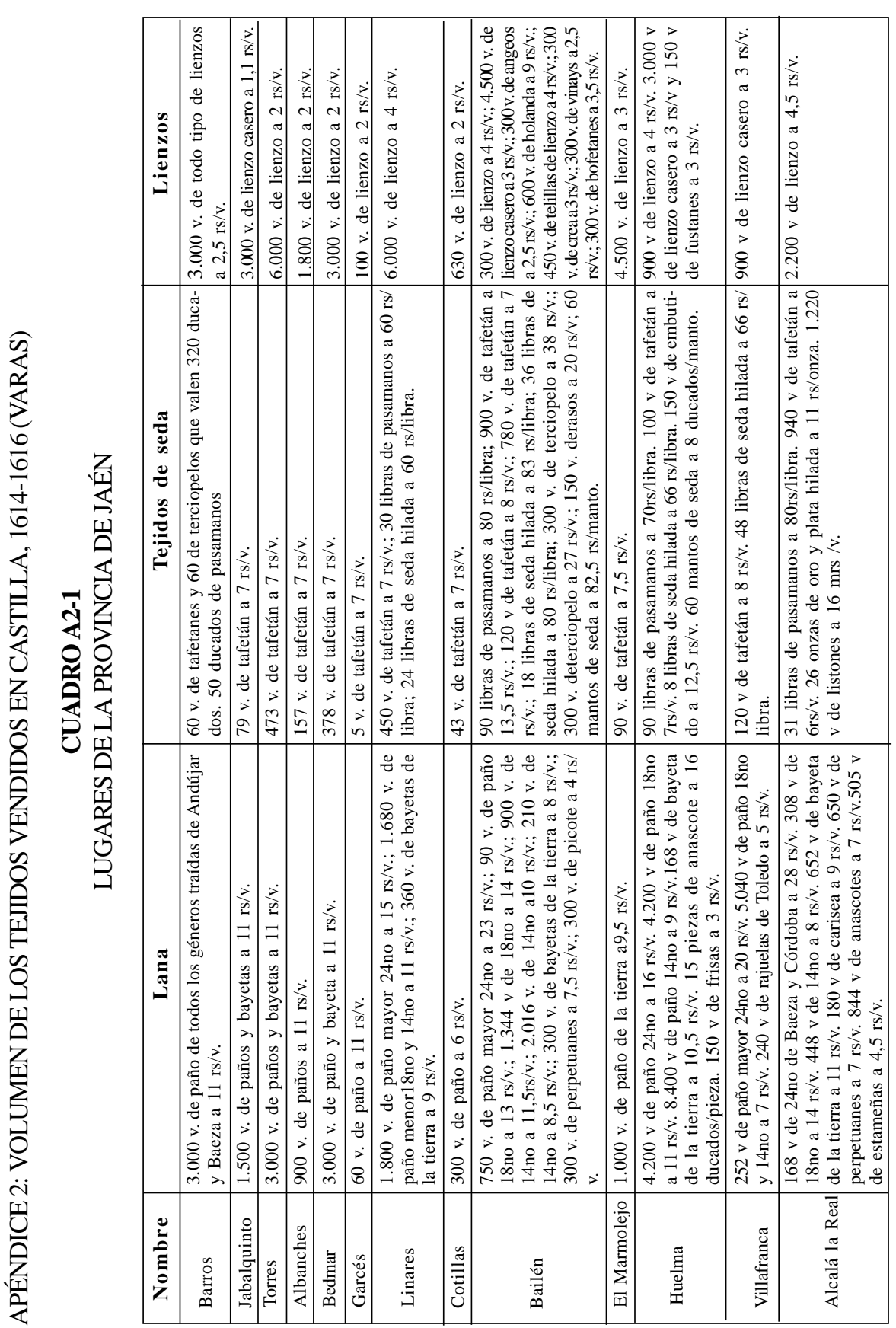




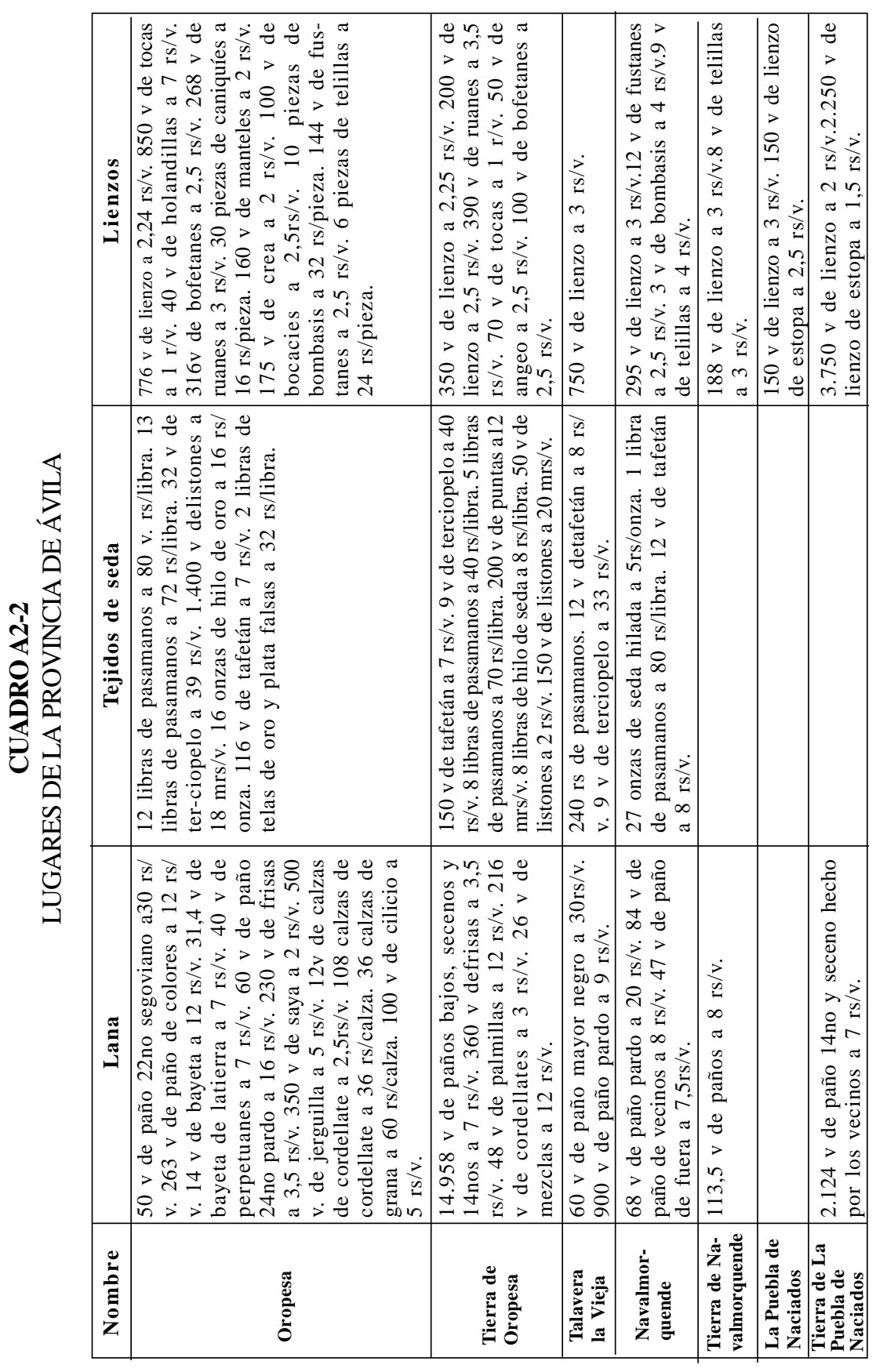




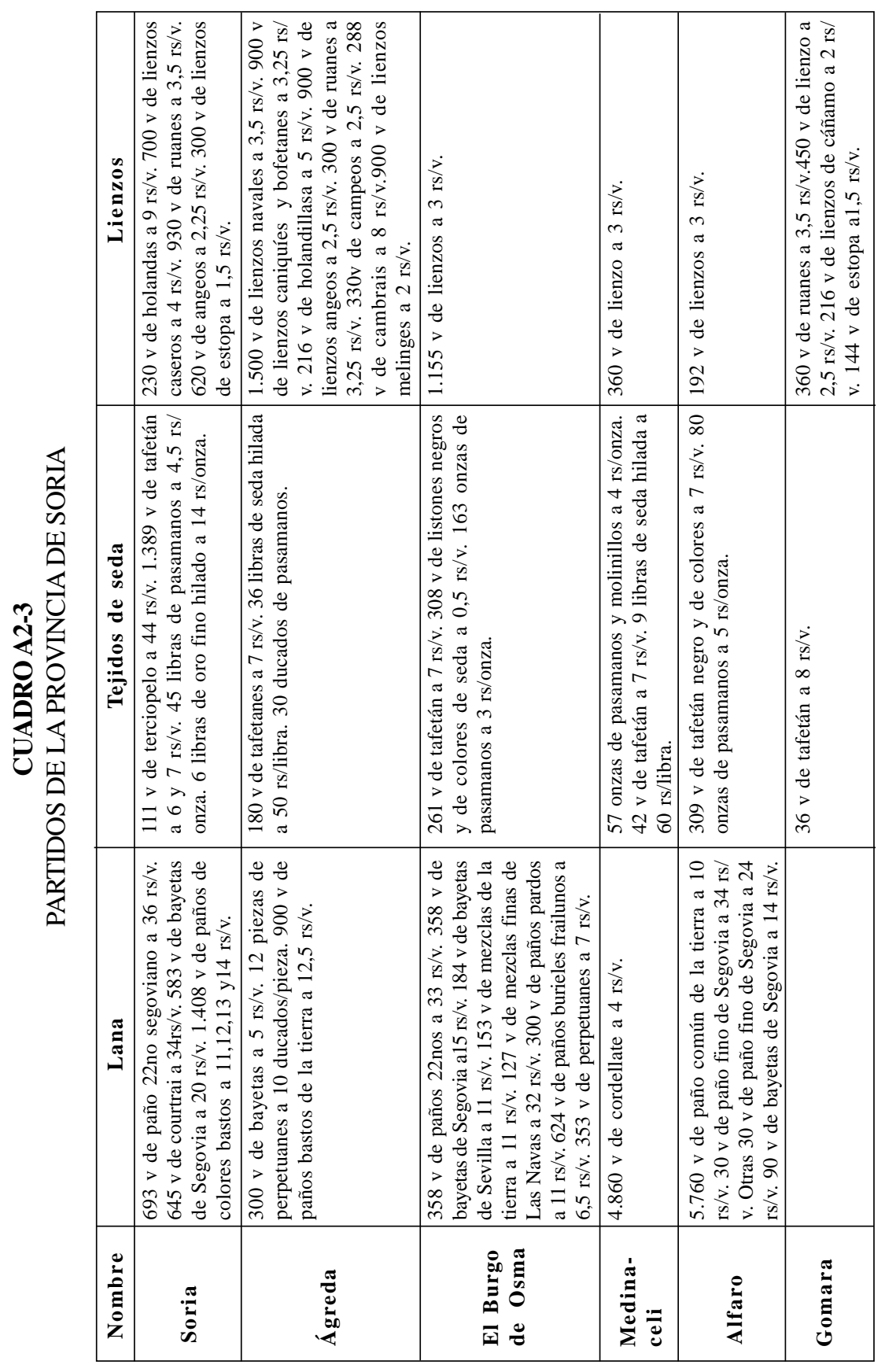


JOSÉ IGNACIO ANDRÉS UCENDO

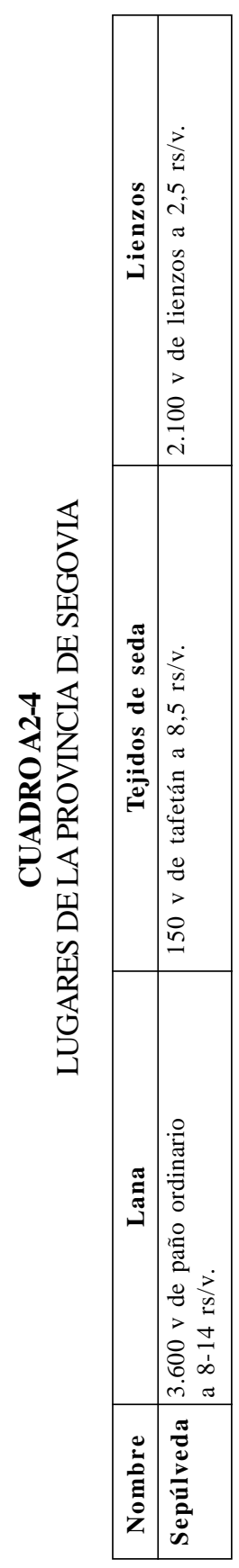

